ISSN: 0213-2079 - ISSN electrónico: 2386-3889

DOI: http://dx.doi.org/10.14201/shhmo201537235268

\title{
POLÍTICA PÚBLICA Y PROTECCIONISMO CORPORATIVO: INSTITUCIONES REGIONALES Y GREMIOS TEXTILES EN ARAGÓN DURANTE EL SIGLO XVII ${ }^{1}$
}

\section{Public Policy and Corporate Protectionism: Regional Insti- tutions and Textile Guilds in Seventeenth Century Aragon}

\author{
José Antonio MATEOS ROYO \\ Universidad de Zaragoza \\ Correo-e:jmateos@unizar.es
}

RESUMEN: Este trabajo defiende a través de un estudio regional que la actuación de los gremios artesanales pudo responder a su adaptación a cambiantes factores económicos e institucionales. Esta flexibilidad limitaría la incidencia autónoma y regular de estos gremios sobre economías regionales o estatales en Europa durante la Edad Moderna. Pese a su aportación positiva al crecimiento económico en el siglo xVI, los gremios textiles se estancaron técnicamente y restringieron la competencia en los mercados urbanos de mercancías y trabajo ante el declive de la economía aragonesa durante el siglo XVII. Estas medidas redujeron la calidad y elevaron el coste de la producción textil regional. Conscientes de sus negativas consecuencias, las instituciones públicas aragonesas toleraron estas estrategias con limitaciones al considerar a los gremios necesarios para organizar la producción y el mercado urbanos de manufacturas.

Palabras clave: Política pública; gremios textiles; Aragón; siglo Xvir.

1. Este artículo forma parte del proyecto de investigación HAR2011-29036-C02-01, financiado por el Ministerio español de Economía y Competitividad. El autor desea agradecer las sugerencias recibidas de los evaluadores anónimos de la revista Studia Historica. Historia Moderna. 
JOSÉ ANTONIO MATEOS ROYO

POLÍTICA PÚBLICA Y PROTECCIONISMO CORPORATIVO:

INSTITUCIONES REGIONALES Y GREMIOS TEXTILES EN ARAGÓN DURANTE EL SIGLO XVII

ABSTRACT: Based on a regional case study, this article will argue that the craft guilds could respond adaptively to changing economic and institutional factors. This flexibility would limit any independent and regular impact of these guilds on regional or state economies in early modern Europe. Having contributed to economic growth in the sixteenth century, the Aragonese textile guilds fell prey to technological stagnation in the seventeenth, while restricting competition in urban product and labour markets as the region's economy contracted. Their actions thus undermined quality and raised the cost of domestic manufactures. The regional institutions nevertheless tolerated these strategies within certain limits, because they saw the guilds as necessary to organize urban markets and production.

Key words: Public policy; Textile guilds; Aragon; Seventeenth century.

\section{INTRODUCCIÓN}

Durante las últimas décadas, el papel ejercido por los gremios artesanales en la evolución económica de Europa durante la Edad Moderna ha suscitado un creciente debate en la Historiografía europea. La visión reinante, que consideraba a los gremios como frenos permanentes al crecimiento económico por su conservadurismo técnico, restricción de la competencia y actividades rentistas, comenzó a cambiar en la década de 1980. Centrados sus estudios en ciudades francesas, los historiadores anglo-americanos Kaplan, Farr y Sonenscher caracterizaron a estos gremios como instituciones adaptadas a coyunturas cambiantes; pero sin incidencia real en la economía ${ }^{2}$. Epstein proporcionó una visión más innovadora de los gremios a fines de la década de 1990 al moderar su capacidad restrictiva sobre el mercado de trabajo, que juzgaba necesaria para la transmisión de habilidades, y defender su capacidad de incorporar tecnología si contaban con el apoyo de instituciones públicas ${ }^{3}$. Esta teoría promovió un creciente debate historiográfico, con dos posiciones muy enfrentadas. Entre otros historiadores y economistas, la visión negativa tradicional de los gremios ha sido reivindicada principalmente por Ogilvie ${ }^{4}$.

2. Kaplan, S. L.: «Réflexions sur la police du monde du travail», Revne historique, 261, 1979, pp. 17-77 y La fin des corporations. París, 2001; Sonenscher, M.: Work and Wages: Natural Law, Politics and the Eighteenth-century French Trades. Cambridge, 1989; FARr, J.: Hands of Honor: Artisans and their World in Dijon, 1550-1650. Nueva York, $1988 \mathrm{y}$ "On the Shop Floor: Guilds, Artisans and the European Market Economy, 1350-1750», Journal of Early Modern History, 1, 1997, pp. 24-54.

3. Epstein, S. R.: «Craft Guilds, Apprenticeship, and Technological Change in Preindustrial Europe», The Journal of Economic History, 58:3, 1998, pp. 684-713.

4. OgiLvie, S.: "Guilds, efficiency, and social capital: evidence from German proto-industry», The Economic History Review, 57:2, 2004, pp. 286-333. 
JOSÉ ANTONIO MATEOS ROYO

POLÍTICA PÚBLICA Y PROTECCIONISMO CORPORATIVO:

INSTITUCIONES REGIONALES Y GREMIOS TEXTILES EN ARAGÓN DURANTE EL SIGLO XVII

El mismo Epstein amplió su teoría inicial con nuevos planteamientos, publicados póstumamente en 2008 tras su reconstrucción por Prak ${ }^{5}$. Los gremios no solo habrían constituido una respuesta eficaz al mal funcionamiento de gobiernos y mercados locales en la Baja Edad Media, sino contribuido al crecimiento económico de Europa en la Edad Moderna reduciendo los costes de transacción por tres vías: la creación de un entorno estable para la formación de capital humano, la coordinación de procesos de producción complejos y la reducción de asimetrías de información entre productores y consumidores al controlar la calidad y fijar el precio de venta de manufacturas, factor esencial para el desarrollo del comercio a larga distancia. Con distintos matices propios, esta visión positiva de los gremios alumbrada por Epstein ha sido defendida por investigadores como Lucassen, de Moor, Pfister, Lis y Soly 6 .

Centrados en el análisis de los gremios urbanos, los estudios aportados en defensa de ambos planteamientos remiten a períodos históricos y regiones concretas. Sin embargo, en un espacio tan extenso como Europa, los gremios disponían de distinto acceso a recursos naturales y humanos según su localización geográfica. Durante un período tan dilatado como la Edad Moderna, atravesaron situaciones económicas muy diferentes que condicionaron sus decisiones y logros. Especialmente, actuaron bajo marcos institucionales con distintas características y evoluciones regionales. Según defendieron North y Epstein, el Estado y las elites locales reformaron las normas que regían el mercado mediante su control de las instituciones públicas para adaptarlas a sus intereses fiscales y comerciales; pero preservando cierto consenso social que asegurase el crecimiento económico ${ }^{7}$. Como el estudio mostrará, la exploración de las políticas públicas resulta esencial para comprender no solo las funciones reales de los gremios, sino su autonomía y capacidad para generar crecimiento o estancamiento económico.

Como aportación al debate, poco abordado por la Historiografía española ${ }^{8}$, este trabajo analiza el desempeño de los gremios textiles urbanos en una región

5. Epstein, S. R. y Prak, M. (eds.): Guilds, Innovation and the European Economy, 1400-1800. Cambridge, 2008.

6. Ibidem, Prak, M. Lis, C. Lucassen, J. y Soly, H. (eds.): Craft Guilds in the Early Modern Low Countries. Work, Power and Representation. Londres, 2006; Moor, T. de: «The Silent Revolution: A New Perspective on the Emergence of Commons, Guilds and other forms of Corporate Collective action in Western Europe», International Review of Social History, 53, 2008, pp. 179-212.

7. NorTH, D. C.: «Institutions, Transaction Costs and Productivity in the Long Run", Economic Inquiry, 25, 3, 1987, pp. 419-428; EpsTEIN, S. R.: Freedom and Growth: the Rise of States and Markets in Europe, 1300-1750. Londres, 2000.

8. Centradas en los gremios urbanos, las principales aportaciones han criticado la corriente revisionista, sobre todo en GonZÁlez ArCE, J. D.: «Los gremios contra la construcción del libre mercado. La industria textil de Segovia a fines del siglo Xv y principios del siglo XvI», Revista de Historia Industrial, XIX, 42, 2010, pp. 15-42. Con mayor moderación, en Yun Casalilla, B.: 
JOSÉ ANTONIO MATEOS ROYO

POLÍTICA PÚBLICA Y PROTECCIONISMO CORPORATIVO:

INSTITUCIONES REGIONALES Y GREMIOS TEXTILES EN ARAGÓN DURANTE EL SIGLO XVII

española mediante su cumplimiento de las tres contribuciones principales de los gremios a la economía europea en la Edad Moderna, según Epstein: atracción de capital y tecnología para coordinar procesos productivos más complejos, regulación del mercado laboral que mejore la formación del artesano y supervisión del mercado de manufacturas que reduzca los costes de transacción. Al carecer de datos que permitan medir las consecuencias de la gestión de estos gremios sobre la negociación y cumplimiento de contratos o la obtención de información sobre precios y calidad de productos forasteros, su incidencia sobre los costes de transacción en este ámbito geográfico será estimada mediante su capacidad para garantizar la calidad de sus propios textiles a través de sus controles o marcas y para promover mayores aranceles de importación u otros obstáculos que afectasen al precio de manufacturas forasteras en el mercado regional.

La región y el período elegidos para el estudio, el reino de Aragón durante el siglo xviI, permiten vincular este debate europeo al de la decadencia económica de España al plantearse en qué medida la actuación gremial aceleró el fuerte declive de la producción manufacturera urbana en esta centuria ${ }^{9}$. Orientada a abastecer el mercado regional pero con cierta capacidad exportadora, la pañería gremial tradicional aumentó notablemente en Aragón su producción durante el siglo XvI gracias a la mejor adecuación a la demanda del mercado, formación de los artesanos y adopción de innovaciones técnicas ${ }^{10}$. Sin embargo, decayó gravemente ante la competencia extranjera durante el siglo xvII, sobre todo desde $1650^{11}$. Resulta pertinente indagar si este declive vino motivado preferentemente por la gestión gremial en torno a los aspectos arriba citados, que presenta claras diferencias entre las ciudades grandes y pequeñas, o por la influencia de relevantes factores económicos e institucionales.

En este sentido, integrado en la incipiente monarquía hispánica surgida de la unión dinástica de las Coronas de Castilla y Aragón a fines del siglo xv, Aragón preservó sus leyes e instituciones hasta su abolición por la nueva monarquía borbónica en 1707. Varias instituciones públicas regionales adoptaron medidas económicas que afectaron a los gremios textiles. Este estudio se centrará en las tres más influyentes: las Cortes, la Diputación y los municipios. A diferencia de

«Manufacturas, mercado interior y redes urbanas: recesión, reajuste y rigideces», en ALCALÁ-ZAMORA, J. y Belenguer, E. (coords.): Calderón de la Barca y la España del Barroco, vol. I. Madrid, 2001, pp. $125-126$.

9. Sobre este proceso, Marcos Martín, A.: España en los siglos XVI, XVII y XVIII. Economía y sociedad. Barcelona, 2000, pp. 512-530.

10. Desportes Bielsa, P.: La industria textil en Zaragoza en el siglo XVI. Zaragoza, 1999, pp. 46-209.

11. Peiró Arroyo, A.: «Comercio de trigo y desindustrialización: las relaciones económicas entre Aragón y Cataluña», en Las relaciones económicas entre Aragón y Cataluña (siglos XVIII-XX). Huesca, 1990, pp. 42-51. 
JOSÉ ANTONIO MATEOS ROYO

POLÍTICA PÚBLICA Y PROTECCIONISMO CORPORATIVO:

INSTITUCIONES REGIONALES Y GREMIOS TEXTILES EN ARAGÓN DURANTE EL SIGLO XVII

Castilla, Cataluña y Valencia, las Cortes aragonesas siguieron activas a fines de esta centuria y promovieron en 1677-78 y 1684-86 enconados debates económicos, que incluyeron valoraciones de la actividad gremial. La Diputación, comité permanente formado por delegados de los cuatro estamentos representados en Cortes (alta y baja nobleza, clero y ciudadanos), asumía el gobierno diario de Aragón y el cumplimiento de las leyes aprobadas por el Parlamento. Su poder político creció conforme se espaciaron las convocatorias de Cortes. Los municipios aplicaban estas leyes y supervisaban la actividad gremial en los mercados locales.

\section{Atracción de CAPITAL E INNOVACión TÉCNICA}

Distintas causas provocaron que los gremios textiles experimentasen en Aragón serias dificultades durante el siglo Xvir para acceder al capital que financiase una producción competitiva y una renovación técnica comparables a las practicadas durante la centuria anterior, especialmente en Zaragoza ${ }^{12}$. Proceso más generalizado aún que en Castilla a fines del siglo xvi ${ }^{13}$, la burguesía mercantil aragonesa entró en quiebra hacia 1580. Mas interesados los grandes comerciantes en arrendar rentas señoriales y exportar materias primas, solo medianos comerciantes invirtieron en la industria textil y unos pocos se especializaron en esta actividad durante el siglo xvi. Sin embargo, la desaparición de esta burguesía redujo los préstamos de capital que recibían los principales inversores de la industria textil: los pelaires y tintoreros. $\mathrm{Ni}$ los comerciantes genoveses que asumieron el control de las transacciones en Aragón hasta 1620 ni los mercaderes franceses que les sucedieron el resto del siglo XVII destinaron capital a las manufacturas aragonesas ${ }^{14}$. La creación de una tupida red profesional desde 1610 y su constante crecimiento desde 1620 permitió a los mercaderes franceses controlar la venta minorista e introducir sus manufacturas, al igual que hacían desde fines del xvi en la vecina Cataluña ${ }^{15}$. Como resultado, si en 1626 la mayoría de las importaciones textiles aragonesas procedían de Cataluña, Valencia y Flandes, las manufacturas francesas predominaron durante toda la segunda mitad del siglo XviI ${ }^{16}$. Tejidos y lencería suponían un $29,77 \%$ y $21,91 \%$ de las importaciones aragonesas de Francia en 1675. El arriendo del cobro de rentas

12. Desportes Bielsa, op. cit., pp. 192-209, 227-228.

13. Ruiz Martín, F.: La banca en España en 1782. Una historia económica del banco de España. Madrid, 1970, pp. 27, 47.

14. Gómez Zorraquino, J. I.: La burguesía mercantil en el Aragón de los siglos XVI y XVII (1516-1652). Zaragoza, 1987.

15. Archivo de la Diputación provincial de Zaragoza [en adelante ADZ], ms. 722, fol. 487v. Sobre Cataluña, Duran Pujol, M.: «Oferta y consumo de tejidos en Cataluña en la segunda mitad del siglo XVII», Revista de Historia Económica, XXI, 4, 2003, pp. 69-72.

16. SÁncheZ Molledo, J. M.: Arbitristas aragoneses de los siglos XVI y XVII. Textos. Zaragoza, 2009, p. 41 y ADZ, ms. 451, fol. 265r-v, 268r, 329r-330v. 
JOSÉ ANTONIO MATEOS ROYO

POLÍTICA PÚBLICA Y PROTECCIONISMO CORPORATIVO:

INSTITUCIONES REGIONALES Y GREMIOS TEXTILES EN ARAGÓN DURANTE EL SIGLO XVII

señoriales, diezmos y primicias a señores laicos y eclesiásticos permitió a estos mercaderes controlar el mercado regional de lana, artículo que suponía el $77.95 \%$ de las exportaciones aragonesas a Francia en 1675 por su fuerte competitividad exterior ${ }^{17}$. Pese a su gradual recuperación durante la segunda mitad de la centuria, la burguesía mercantil aragonesa se centró en operaciones menos comerciales y más rentistas sin eliminar el control de las transacciones por los mercaderes fran$\operatorname{ceses}^{18}$. Proceso ya iniciado a fines del siglo xvi, descendientes de las familias más enriquecidas de artesanos textiles de Zaragoza desviaron parte de sus beneficios durante el siglo XvII a actividades menos productivas como el arriendo de tierras e inmuebles para lograr acceder a la categoría de mercader, adquirir la infanzonía y trabar relaciones matrimoniales con la nobleza ${ }^{19}$.

El retroceso de la inversión se vio agravado por la fuerte caída de la población ${ }^{20}$. Tras alcanzar el cenit de su crecimiento demográfico a fines del siglo XvI, este declive fue precipitado en 1610, cuando la expulsión de los moriscos decretada por Felipe III afectó a unas 14.000 familias, un 18,85\% de la población. A pesar de esta sangría demográfica, si un recuento general en 1495 fijaba 51.450 fuegos o unidades fiscales, una estimación similar efectuada entre 1646 y 1650 mostró un crecimiento hasta 79.729 hogares ${ }^{21}$. La peste bubónica que se difundió por Aragón entre 1648 y 1654 produjo gran mortalidad, especialmente en las ciudades. El Parlamento aragonés calculó en 1677 que solo existían 60.000 fuegos $^{22}$. La recuperación solo comenzó en las dos últimas décadas del siglo XviI hasta alcanzar Aragón 76.613 fuegos en 1711.

Amén de la sangría demográfica, la expulsión de los moriscos provocó una fuerte caída de la producción, inversión y demanda. Dañó redes comerciales y aumentó el endeudamiento de muchos municipios, obligados a asumir las deudas

17. ADZ, ms. 734, fol. 276r-280r, 405r-408r. Las razones de esta competitividad de la lana aragonesa durante la Edad Moderna serían similares a las expuestas para Castilla en García SANZ, A.: «Competitivos en lanas, pero no en paños: lana para la exportación y lana para los telares nacionales en la España del Antiguo Régimen», Revista de Historia Económica, XII, 2, 1994, pp. 418-419.

18. Gómez Zorraquino, J. I.: Zaragoza y el capital comercial. La burguesía mercantil en el Aragón de la segunda mitad del siglo XVII. Zaragoza, 1987, pp. 74-102. Entre estas actividades destacan la adquisición de tierras de nobles, la compra y arriendo de inmuebles y la concesión de préstamos a la monarquía.

19. Desportes Bielsa, op. cit., pp. 221-223. Esta ascensión social de artesanos enriquecidos se dio con anterioridad en otras grandes ciudades de la Corona de Aragón, como Valencia. Véase Navarro Espinach, G.: «Los negocios de la industria precapitalista valenciana en los siglos XIV-XVI», Revista d'Historia Medieval, 11, 2000, pp. 98-101.

20. Salas Ausens J. A.: «La evolución demográfica aragonesa en los siglos Xvi y XviI», en NADAL Oller, J. (ed.): La evolución demográfica bajo los Austrias. Alicante, 1991, pp. 169-179.

21. Ibidem; Dormer, D. J.: Discursos históricos-políticos. Zaragoza, 1989 (facsímil del original impreso en 1684), pp. 131-133.

22. Biblioteca de la Real Academia de Historia, Colección Nasarre, ms. 11-1-1, fol. 547r-562v. 
JOSÉ ANTONIO MATEOS ROYO

POLÍTICA PÚBLICA Y PROTECCIONISMO CORPORATIVO:

INSTITUCIONES REGIONALES Y GREMIOS TEXTILES EN ARAGÓN DURANTE EL SIGLO XVII

de los concejos moriscos. Al ser los moriscos mayoritariamente vasallos de señorío laico, su marcha redujo drásticamente las rentas feudales y agravó las dificultades financieras de la alta nobleza ${ }^{23}$. La bancarrota de esta nobleza deterioró el sistema crediticio, que había drenado mucho capital a actividades productivas durante el siglo xvi. Esta erosión se evidencia en la evolución de la deuda municipal a largo plazo $^{24}$. Incluso los créditos contraídos por los concejos de realengo, considerados más solventes que aquellos bajo señorío, fueron donados o vendidos al clero por sus propietarios -ciudadanos e infanzones-ante el temor a impagos o bruscos descensos de su tasa de interés. Estas expectativas se confirmaron ante la bancarrota sufrida por los municipios a lo largo del siglo xvir, que alcanzó las principales ciudades de realengo en la segunda mitad y forzó a rebajar estas tasas del $5 \%$ usual en el siglo xvi al 3\% o menos. Las bancarrotas de nobleza y municipios constriñeron la oferta de capital de grupos rentistas y encarecieron los préstamos a corto plazo. La Diputación ya recomendó a las Cortes de 1626 fijar un interés máximo del $7,5 \%$ para contener las frecuentes prácticas usurarias. Tras constatar que ciertos mercaderes prestaban a corto plazo al $20 \%$ sin disponer de un banco con reservas de dinero, dicho Parlamento estableció que estos solo podían confiar su dinero a un interés máximo del 7\% a los banqueros o cambistas, únicos autorizados a conceder créditos a corto plazo a particulares y percibir hasta un $9 \%$ de interés ${ }^{25}$.

Por último, la creciente fiscalidad real y municipal aplicada durante la centuria mermó el capital circulante, la capacidad de ahorro y autofinanciación de los artesanos junto con la capacidad adquisitiva de la población que la sustentaba. Cada vez más endeudados, los municipios elevaron sus impuestos. Si villas y aldeas preferían la tributación directa, las ciudades aumentaron los impuestos sobre alimentos básicos, en especial el trigo y la carne ${ }^{26}$. Como se verá, aplicada con especial fuerza durante el segundo y último cuarto del siglo xvir, la fiscalidad real combinó estas contribuciones municipales con impuestos sobre la producción textil y mayores aranceles aduaneros que encarecieron los costes de fabricación y dificultaron la comercialización de las manufacturas aragonesas en los mercados españoles y extranjeros.

Conscientes de la carencia de capital que aquejaba a la industria, ya las Cortes de 1626 intentaron fomentar la participación de la nobleza en el comercio y la producción textil de lana y seda durante el siglo XviI mediante el

23. Abadía Irache, A.: La enajenación de rentas señoriales en el reino de Aragón. Zaragoza, 1998, pp. 362-430.

24. Mateos Royo, J. A.: «Propios, arbitrios y comunales. la hacienda municipal en el reino de Aragón durante los siglos XVI y XVII", Revista de Historia Económica, XXI, 3, 2003, pp. 62-72.

25. Sánchez Molledo, op. cit., pp. 49-50; Savall y Dronda P. y Penén Debesa, S.: Fueros, observancias y actos de Corte del reino de Aragón, t. I. Zaragoza, 1866, p. 461.

26. Mateos Royo, J. A.: «Propios...», op. cit., pp. 58-59. 
JOSÉ ANTONIO MATEOS ROYO

POLÍTICA PÚBLICA Y PROTECCIONISMO CORPORATIVO:

INSTITUCIONES REGIONALES Y GREMIOS TEXTILES EN ARAGÓN DURANTE EL SIGLO XVII

reconocimiento de sus títulos y honores si no vendían o elaboraban tejidos en una tienda, taller o su propio domicilio. Sin embargo, como especificaron las Cortes de 1677-78, su ejercicio les impedía ejercer oficios públicos en Aragón o representar a la baja nobleza en su Parlamento ${ }^{27}$. Estas limitaciones chocaban con el creciente interés de la alta y baja nobleza por acceder a cargos públicos en las administraciones regional, estatal y colonial, patentes en su reserva parcial para naturales de Aragón obtenida de la monarquía hispánica en las Cortes de 1626 y $1645-46$ a cambio de aprobar los subsidios solicitados ${ }^{28}$. La reiteración de esta ley aprobada en 1626 en las Cortes de 1677-78 y 1684-86 ante las quejas continuas de mercaderes y arbitristas por su incumplimiento revela la existencia de barreras al ascenso social de comerciantes interesados en la industria textili ${ }^{29}$. Un grupo de fabricantes reclamó en 1674 al virrey don Juan José de Austria ver reconocidos los mismos honores y títulos a los que tenían derecho a los comerciantes ${ }^{30}$. Compuesta básicamente por infanzones, la burguesía mercantil zaragozana resurgida en la segunda mitad del siglo descartó la posesión de telares -incluso por personas interpuestas-al valorar las escasas expectativas de beneficio frente a los inconvenientes generados en sus deseos de emparentar con la alta nobleza o acceder a cargos públicos ${ }^{31}$.

Proceso común a las ciudades españolas durante el Antiguo Régimen, artesanos y pequeños comerciantes fueron también relegados de la política local. Acaecido ya en Castilla durante la Baja Edad Media ${ }^{32}$, revistió mayor intensidad en Valencia y Aragón que en Cataluña durante la Edad Moderna ${ }^{33}$. Salvo en Zaragoza, donde la nobleza quedó excluida de la elite municipal, el poder público local era ejercido en Aragón por los «ciudadanos honrados», burgueses acomodados y pequeños nobles dedicados al comercio y profesiones liberales, así como propietarios y rentistas agrarios. Si estos «ciudadanos honrados» ya controlaban los principales cargos municipales gracias al nuevo método electivo

27. Savall y Dronda P. y Penén Debesa, S., op. cit., t. I, pp. 454, 517-518, 531; t. II, pp. 409-410.

28. Idem, t. I, pp. $456,497$.

29. Idem, t. I, pp. 517-8, 531; ADZ, ms. 451, fo. 1301v-1302r y Biblioteca Nacional [en adelante $\mathrm{BN}], \mathrm{VE} 209-60$.

30. BN, VE 180-40; Perdices de Blas, L. y Sánchez Molledo, J. M. (eds.): Arbitrios sobre la economía aragonesa del siglo XVII. Zaragoza, 2007, pp. 145-146.

31. Gómez Zorraquino, op. cit., pp. 74-127.

32. Monsalvo Antón, J. M.: «Aproximación al estudio del poder gremial en Castilla durante la Baja Edad Media: un escenario de debilidad», En la España medieval, 25, 2002, pp. 135-176.

33. Sobre Valencia, Casey, J.: El reino de Valencia en el siglo XVII. Madrid, 1983, pp. 177-180. Para Cataluña, Torres, X.: «La Barcelona menestral en temps dels Austries», en Barcelona en temps dels Austries. La vita a la ciutat en el Renaixement i el Barroc (1492-1711). Barcelona, 1996, pp. 41-42 y Sugranies, J. A.: «La industria de la seda a Reus», en El món de la seda $i$ Catalunya. Barcelona, 1991, p. 213. 
JOSÉ ANTONIO MATEOS ROYO

POLÍTICA PÚBLICA Y PROTECCIONISMO CORPORATIVO:

INSTITUCIONES REGIONALES Y GREMIOS TEXTILES EN ARAGÓN DURANTE EL SIGLO XVII

introducido a mediados del siglo xv, elevaron en el siglo xvis los niveles de riqueza requeridos para acceder a estos puestos permitiendo solo el ingreso a aquellos aspirantes ya asimilados a las categorías de ciudadanos e infanzones gracias a su riqueza; pero excluyendo a los artesanos activos. Si Zaragoza prohibía su ejercicio a toda persona que hubiese practicado un oficio manual o la venta minorista, las restantes ciudades solían exigir su abandono previo durante períodos entre dos y diez años. En ciudades menos restrictivas como Tarazona, Barbastro o Alcañiz, desempeñar un cargo público impedía tener tienda abierta o al menos trabajar en esta ${ }^{34}$.

Pese a los esfuerzos de las Cortes, los gremios textiles frenaron todo intento de abrir talleres y contratar trabajadores libres por parte de mercaderes aragoneses en las mayores ciudades ante el temor de perder control sobre la producción y venta de manufacturas. Estos mercaderes únicamente podían contratar miembros del gremio si ingresaban en este tras pasar un examen de maestría, condición que implicaba un descenso de su status social ${ }^{35}$. Ante estas barreras, como ya hacían en el siglo XVI, los mercaderes continuaron prestando dinero o materias primas a los artesanos textiles sin asumir costes fijos, pero fueron endureciendo las contraprestaciones exigidas conforme estos padecían mayores necesidades de capital. Los pelaires denunciaron en las Cortes de 1626 que los mercaderes utilizaban la escasez de crédito a corto plazo en Aragón para practicar la usura al cobrar sus préstamos mediante el producto acabado tasado a bajo precio, reduciendo los beneficios y capacidad de inversión de estos artesanos ${ }^{36}$.

La declinante demanda interna y la creciente competencia extranjera agravaron los problemas de financiación de los gremios textiles durante la segunda mitad del siglo XviI, sobre todo en las pequeñas ciudades. En 1666 los pelaires de Albarracín solo podían fabricar sus paños acumulando deudas con los mercaderes que les facilitaban lana y los tejedores ${ }^{37}$. En 1691 los artesanos del cáñamo de Daroca dependían de comerciantes que les aportaban la materia prima ${ }^{38}$. En 1692 los pelaires de Teruel firmaron un acuerdo con sus acreedores ante su fuerte endeudamiento ${ }^{39}$. Resultado de este proceso, al igual que sucedía en otras ciudades

34. Gómez Zorraquino, J. I.: «Del concejo foral al ayuntamiento borbónico. La mudanza en el poder municipal (siglos XVI-XvIII)», en El municipio en Aragón. 25 siglos de Historia. Zaragoza, 2004, pp. 116-124.

35. Archivo Municipal de Zaragoza [en adelante AMZ], Caja 7079, 120-2, fol. 2r-10r.

36. Dormer, op. cit., p. 34.

37. ADZ, ms. 523, fol. 215r.

38. Mateos Royo, J. A.: Auge y decadencia de un municipio aragonés: el concejo de Daroca en los siglos XVI y XVII, Daroca, 1997, pp. 417-418.

39. Vega y Luque, C. L. de la: «Historia y evolución de los gremios de Teruel», Teruel, 54, 1975, p. 120. 
JOSÉ ANTONIO MATEOS ROYO

POLÍTICA PÚBLICA Y PROTECCIONISMO CORPORATIVO:

INSTITUCIONES REGIONALES Y GREMIOS TEXTILES EN ARAGÓN DURANTE EL SIGLO XVII

de la Castilla interior ${ }^{40}$, los mercaderes lograron una mayor dirección del proceso productivo en detrimento de los artesanos; pero probablemente en distinto grado según el tipo de tejidos. La penetración del capital mercantil sería más factible en ramas de la producción textil como la basada en fibras vegetales que preservaban una sustancial demanda externa e interna debido a su baratura y requerían escasas inversiones en materias primas y utillaje. Como revela el caso de Daroca, su control del proceso productivo fue facilitado por la débil oposición de gremios con una formación relativamente reciente. La menor complejidad técnica de este sector textil también facilitaría que algunos mercaderes extendiesen estas prácticas al medio rural durante la segunda mitad del siglo xvir, utilizando tanto trabajadores agremiados como no agremiados, al igual que hacían con otros tejidos ${ }^{41}$.

Algunos gremios textiles modificaron sus sistemas productivos para intentar adecuarse a la demanda del mercado, como procedieron los pelaires y tejedores de lana en Barbastro durante el tercer cuarto del siglo Xvir sin alterar sus estatutos ${ }^{42}$. Por lo general, fueron incapaces de adoptar nueva tecnología ante la carencia de capital. Como obraron otras ciudades españolas, algunos municipios reaccionaron facilitando la instalación de fabricantes aragoneses o extranjeros que introducían técnicas importadas de Flandes, Italia o Francia ${ }^{43}$. Utilizaron la novedad de estos procesos técnicos como argumento para prohibir la intromisión de los gremios locales en la organización de su producción o la formación de sus oficiales y aprendices. Favorecida por su mayor demanda y mejor ubicación geográfica para vender la producción, Zaragoza concentró estas tentativas. El municipio logró que el catalán Juan Garriga estableciese en 1629 una fábrica de tejidos de lana y el milanés Antonio Trípoli otra de tejidos de seda en 1680: ambos fabricantes buscaban garantizar la venta de su producción en Aragón, cuyas Cortes prohibieron importar cualquier textil extranjero en 1627-45 y 1678-85. Pese a oponerse el gremio de abantaleros, permitió en 1686 al mercader zaragozano Bartolomé Brusau instalar telares para fabricar tejidos de lana similares a los extranjeros ${ }^{44}$.

40. Hernández García, R.: La industria textil en Palencia durante los siglos XVI y XVII. Valladolid, 2007, pp. 104-105.

41. El interés del gremio de mercaderes de Zaragoza por comercializar tejidos producidos en el medio rural aragonés a fines del siglo xviI por campesinos y pelaires se evidencia en ADZ, ms. 580, fo.2334r-2335r. Sobre la evolución de este proceso de protoindustrialización en la España Moderna, GonzÁlez Enciso, A.: «Les facettes de la pluriactivité dans les industries rurales de l'Espagne moderne», en Minovez, J. M., Verna, C. y Hilaire-Pérez, L. (dirs.): Les industries rurales dans l'Europe médiévale et moderne. Toulouse, 2013, pp. 203-221.

42. Salas Ausens, J. A.: La población..., op. cit., p. 295.

43. Véase el temprano ejemplo de Murcia en Millares Martínez, P.: «La sedería murciana en el siglo XviI: progresos y dificultades», en ARANDA PÉrez, F. J. (coord.): La declinación de la monarquía hispánica en el siglo XVII. Cuenca, 2004, pp. 545-546.

44. Redondo Veintemillas, G.: Las corporaciones de artesanos de Zaragoza en el siglo XVII. Zaragoza, 1982, pp. 151-154. 
JOSÉ ANTONIO MATEOS ROYO

POLÍTICA PÚBLICA Y PROTECCIONISMO CORPORATIVO:

INSTITUCIONES REGIONALES Y GREMIOS TEXTILES EN ARAGÓN DURANTE EL SIGLO XVII

En línea con la política mercantilista auspiciada por la monarquía hispánica bajo Carlos II, patente en las actuaciones de las Juntas de comercio surgidas en Madrid y varias ciudades españolas durante las dos décadas finales del siglo XVII, las Cortes de 1677-78 y 1684-86 promovieron la instalación de fabricantes extranjeros en Aragón ${ }^{45}$. Como medio, concedieron a cualquier aragonés o extranjero que aportase una nueva tecnología su patente tras ser examinada por el municipio donde residía ${ }^{46}$. Esta decisión matizaba la oposición a las patentes practicada en la Corona de Aragón durante el siglo XviI por considerarlas monopolios ilegales introducidos por la monarquía hispánica con fines fiscales ${ }^{47}$. Fruto de las dificultades jurídicas, las Cortes de 1677-78 fijaron en solo dos años la validez de la patente, extendidos a tres en 1684-86. Pese a su escasa duración frente a los veinte años concedidos en Castilla, la incidencia de la patente fue reforzada al facilitar a los fabricantes extranjeros asentados en Aragón vender sus productos en Castilla por haberse producido en territorio español. Estos fabricantes procedían mayoritariamente de Francia y ocasionalmente de territorios italianos bajo soberanía hispánica. Su aplicación permitió adoptar técnicas novedosas en la industria textil; pero fue efectuada al margen de los gremios e incidió poco en la producción regional ${ }^{48}$.

Estas dificultades de renovación técnica acarrearon un profundo declive y remodelación de la producción textil en Aragón durante el siglo XviI. Por desgracia, la carencia de figuras fiscales aplicadas sistemáticamente a las manufacturas como las existentes en Castilla y otros territorios de la Corona de Aragón ha impedido disponer de fuentes que permitan una estimación cuantitativa de su evolución y composición. Como mejor opción, se ha reflejado este proceso en la tabla 1 mediante la estimación de los talleres artesanales activos en Barbastro en 1619 y 1680 y en Zaragoza en 1642 y 1721 a través de recuentos municipales elaborados con fines fiscales en ambas ciudades.

45. Kamen, H.: La España de Carlos II. Barcelona, 1981, pp. 122-140, 443; Chacón Jiménez, F.: «El artesanado y la economía urbana en el siglo XviI», en Jover ZAMORA, J. M. (dir.): La crisis del siglo XVII. Historia de España Menéndez Pidal, t. XXIII. Madrid, 1989, pp. 305-308 y SÁncheZ BELÉn, J. A.: «Medidas extraordinarias para una crisis económica: las reformas del duque de Medinaceli y del duque de Oropesa a finales del reinado de Carlos II», Trocadero, 23, 2011, pp. 28-34. Si Kamen indicó que la Junta de Comercio primó los intereses de los grandes comerciantes sobre los de los fabricantes, Sánchez Belén sostiene que la oposición gremial cooperó al fracaso de las iniciativas empresariales manufactureras propiciadas por esta institución.

46. Savall y Dronda, P. y Penén Debesa, S., op. cit., t. I, p. 531; t. II, p. 409.

47. Archivo de la Corona de Aragón [en adelante ACA]), Consejo de Aragón [en adelante CA], legs. 141, 162, 415.

48. Véase la nota 44. 
JOSÉ ANTONIO MATEOS ROYO

POLÍTICA PÚBLICA Y PROTECCIONISMO CORPORATIVO:

INSTITUCIONES REGIONALES Y GREMIOS TEXTILES EN ARAGÓN DURANTE EL SIGLO XVII

TABLA 1. Evolución de los talleres artesanales activos en Barbastro y Zaragoza (1619-1721)

\begin{tabular}{lcccc}
\hline & \multicolumn{2}{c}{ Barbastro } & \multicolumn{2}{c}{ Zaragoza } \\
\hline Sectores & 1619 & 1680 & 1642 & 1721 \\
\hline Lana & 61 & 34 & 329 & 89 \\
\hline Seda & 3 & 1 & 156 & 98 \\
\hline Tintorería & 2 & 3 & 17 & 13 \\
\hline Confección & 67 & 39 & 392 & 237 \\
\hline Total del sector textil & 133 & 77 & 894 & 437 \\
\hline Cuero, calzado, fibras vegetales & 49 & 58 & 312 & 212 \\
\hline Madera & 36 & 14 & 163 & 122 \\
\hline Construcción y alfarería & 30 & 17 & 98 & 52 \\
\hline Metal & 23 & 16 & 159 & 147 \\
\hline Alimentación & 19 & 14 & 137 & 102 \\
\hline Otros oficios & 3 & 9 & 149 & 152 \\
\hline Total de otros sectores & 160 & 128 & 1.014 & 785 \\
\hline Total de todos los sectores & 293 & 205 & 1.908 & 1.222 \\
\hline
\end{tabular}

Fuente: Peiró Arroyo, A.: «Comercio...», op. cit., pp. 49-50.

Como apreciación general, el declive de los talleres textiles sobrepasó el sufrido por otros oficios artesanales. Su número total descendió así un 42,10\% en Barbastro entre 1619 y 1680 , y un $51,10 \%$ en Zaragoza entre 1642 y 1721 . La industria de la lana fue la rama textil más afectada al caer sus talleres un 44,3\% en Barbastro y un $72,9 \%$ en Zaragoza. Este declive ganó fuerza en la segunda mitad del siglo XviI, conforme la demanda de tejidos elaborados con fibras vegetales crecía en España y Europa y las manufacturas francesas imponían su mayor competitividad en el mercado regional. Los tejedores y pelaires de Huesca habían reducido en $1716 \mathrm{su}$ número a un 46,15\% de los activos en 1663 y 1673 . Según indican los informes elaborados en 1667 por los municipios de Calcena, Caspe, Daroca, Alcañiz y Albarracín ante una investigación requerida por la Diputación, el declive de la producción fue rápido desde mediados la centuria. En Calcena el concejo estimó que, si 400 familias trabajaban en la industria de la lana en 1640, solo 200 permanecían empleadas en 1667 debido a la caída de la demanda aragonesa y la extinción de sus ventas en mercados tradicionales como a Castilla y Navarra ${ }^{49}$. Las exportaciones de paños de lana fabricados en Zaragoza, Teruel y Albarracín a Francia e Italia efectuadas

49. ADZ, ms., 523, fols. $215-422$. 
JOSÉ ANTONIO MATEOS ROYO

POLÍTICA PÚBLICA Y PROTECCIONISMO CORPORATIVO:

INSTITUCIONES REGIONALES Y GREMIOS TEXTILES EN ARAGÓN DURANTE EL SIGLO XVII

durante la primera mitad del siglo Xvir habían sido también anuladas ya en 1677 por la importación de manufacturas desde el sur de Francia ${ }^{50}$.

Otras ramas textiles conocieron decrecimientos menos significativos en el siglo xviI. Con una expansión menor que la de la lana a mediados de la centuria, los talleres textiles de seda cayeron en Zaragoza un 37,2\% entre 1642 y 1721 . Los dedicados a la confección descendieron un 41,8\% en Barbastro entre 1619 y 1680, así como un 39,5\% en Zaragoza entre 1642 y $1721^{51}$. Orientada a la demanda interna, esta rama textil acusó menos la caída de las exportaciones que la de la lana. Frente a la decadencia de estas actividades textiles que requerían mayor cualificación, la fabricación de diversos artículos (sogas, sacos, alpargatas, jarcias, cestas) con fibras textiles vegetales como cáñamo, lino, estopa y esparto creció en Aragón en el siglo xvir. Tras propiciar la formación de nuevos gremios urbanos a principios de la centuria, proceso inexistente en otras regiones de España ${ }^{52}$, la producción se afianzó en sus décadas finales. Los talleres de cesteros y sogueros en Barbastro pasaron así de 13 en 1619 a 29 en 1680. Las crecientes promociones a la maestría acaecidas en los gremios que trabajaban el cáñamo y lino en Zaragoza entre 1671 y 1710 reflejan la clara revitalización de este sector frente a su estancamiento a mediados de la centuria ${ }^{53}$. Este crecimiento se vio favorecido por la escasa inversión en utillaje y buena disponibilidad de las materias primas esenciales, algunas incluso exportadas como el cáñamo ${ }^{54}$. Junto a los pedidos del ejército castellano, la demanda interna se veía facilitada por su mayor baratura frente a los tejidos de lana ante el menor poder adquisitivo de buena parte de la población aragonesa y la carencia de competencia por parte de productos similares importados.

\section{LA SUPERVISIÓN DEL MERCADO LOCAL: CALIDAD Y PRECIO DE LAS MERCANCÍAS}

Limitados por su debilidad técnica y financiera, los gremios aragoneses perdieron capacidad desde principios del siglo xvII para ofrecer productos competitivos en el mercado regional. Como medida defensiva, aumentaron las trabas a la introducción de manufacturas aragonesas o extranjeras en los mercados locales. La caída del consumo provocada por el declive demográfico y económico, acelerada por la presión fiscal, propició su rápida extensión a artículos de bajo precio y elaboración basta. Las consecuencias generadas por esta estrategia en la calidad

50. BN, VE, 198-47.

51. Peiró Arroyo, A.: "Comercio...», op. cit., pp. 49-51.

52. Chacón Jiménez, F.: «El artesanado...», op. cit., p. 298.

53. Salas Ausens J.A.: La población..., op. cit., p. 293; Redondo Veintemillas, op. cit., pp. 89-90, 268-276.

54. Asso, I. de: Historia de la economía política de Aragón. Zaragoza, 1983 (facsímil del original impreso en 1798), p. 228. 
JOSÉ ANTONIO MATEOS ROYO

POLÍTICA PÚBLICA Y PROTECCIONISMO CORPORATIVO:

INSTITUCIONES REGIONALES Y GREMIOS TEXTILES EN ARAGÓN DURANTE EL SIGLO XVII

y el precio de los tejidos locales no solo evidencian un distinto control gremial del mercado en grandes y pequeñas ciudades, sino su adaptación a las cambiantes políticas fiscales y comerciales de las instituciones públicas aragonesas durante la centuria. Como se verá, la aceptación de este hecho por dichas instituciones matizó su valoración final de la gestión gremial.

Muchos municipios toleraron la erección de estos obstáculos, en especial sobre mercancías que competían con la producción de los gremios locales más numerosos y mejor organizados, para frenar el empobrecimiento del artesanado y la despoblación o evitar alteraciones sociales. En ocasiones, cobraron un canon anual a ciertos gremios por asegurar su monopolio del mercado local. En otras, impusieron a mercancías forasteras nuevos impuestos, abusivas tasaciones de su precio o prohibiciones de venta basadas en su supuesta mala calidad. En general, aumentaron el control del mercado local permitido a los gremios durante todo el siglo xvi. En sus inicios, Zaragoza lideró incluso una campaña política ante el Parlamento aragonés $(1512,1515)$ y el rey $(1522)$ para suprimir sus prácticas monopolistas. Estos intentos triunfaron cuando las Cortes de 1528 y 1533 aprobaron la supresión de los gremios en todo Aragón: solo sus funciones caritativas y religiosas podían continuar ${ }^{55}$. Con especial rapidez en el sector textil, los municipios reinstauraron durante las décadas siguientes los gremios mediante nuevos estatutos que concretaban sus actividades al percatarse de su utilidad para organizar la producción de los oficios urbanos, reconocida públicamente por Zaragoza en $1575^{56}$. Sin embargo, limitaron su regulación del precio de las manufacturas para reducir los costes de transacción. Con mayor frecuencia que en las restantes ciudades aragonesas debido a la mayor demanda, Zaragoza fijó el precio de materias primas -cuero, piel-o productos artesanales y prohibió la reventa de mercancías adquiridas a mercaderes por artesanos para contener la inflación de precios típica de esta centuria ${ }^{57}$. Los municipios confirmaron la actuación de los inspectores gremiales para garantizar la calidad de la producción artesanal. Excepcionalmente Zaragoza creó la "Casa de la Bula», donde dos maestros pelaires desde 1548 más un maestro tintorero desde 1602 designados por oficiales municipales supervisaban la calidad de la producción textil local ${ }^{58}$.

Conforme las trabas de gremios y municipios a la comercialización de manufacturas crecieron desde 1610, desataron la reacción de la Diputación. Esta

55. Desportes Bielsa, op.cit., pp. 246-249; Savall y Dronda, P. y Penén Debesa, S., op. cit., t. I, pp. 229-230.

56. Ibidem; Redondo Veintemillas, op. cit., pp. 82-83.

57. SAn Vicente Pino, A.: Instrumentos para una historia social y económica del trabajo en Zaragoza durante los siglos XV a XVIII, t. I. Zaragoza, 1988, pp. 266-267, 323-325, 353, 377-378, $522-525$.

58. Idem, t. I, pp. 213-217; t. II, pp. 27-34; AMZ, caja 46-7, fo.4r-12r;. 
JOSÉ ANTONIO MATEOS ROYO

POLÍTICA PÚBLICA Y PROTECCIONISMO CORPORATIVO:

INSTITUCIONES REGIONALES Y GREMIOS TEXTILES EN ARAGÓN DURANTE EL SIGLO XVII

institución defendía la moderación arancelaria y el libre tránsito de mercancías aragonesas y extranjeras por el reino. Esta política comercial protegía sus principales ingresos, percibidos como aranceles aduaneros en la frontera. Velaba por los intereses económicos de la nobleza y el clero, mayoría entre sus miembros, como perceptores de rentas, exportadores de productos agrarios e importadores de manufacturas. Dado que diversos fueros o leyes consuetudinarias aprobadas por las Cortes entre los siglos XIII y Xvi prohibían la creación de peajes u otros obstáculos al libre tránsito de mercancías, la Diputación defendió con éxito sus intereses ante la Corte del Justicia de Aragón ${ }^{59}$. Presidida por el Justicia como principal juez en conflictos legales entre el rey y sus súbditos, este tribunal velaba por el cumplimiento de los fueros aragoneses. La Corte del Justicia falló siempre a favor de la Diputación e incluso reconoció en 1623 y 1643 mediante las firmas «Máxima» y «Magna» la validez de sus planteamientos en todo Aragón; pero gremios y municipios siguieron entorpeciendo el tráfico de mercancías ${ }^{60}$.

La fuerte presión fiscal de la monarquía aplicada en Aragón en 1628-52 incidió en esta pugna institucional. Cada vez más endeudados, los municipios aragoneses no podían satisfacer con impuestos la mayoría de los subsidios reales, como durante el siglo xvi. Los estamentos tuvieron que elevar los aranceles percibidos en las aduanas del reino. En defensa de sus intereses, las elites agrarias mantuvieron bajos -en torno a un 5\%- en las Cortes de 1626 y 1645-46 aquellos establecidos sobre la lana y alimentos esenciales de producción regional (trigo, carne) y extranjera (pescado, vino) para favorecer su consumo y exportación. Como contrapartida, las Cortes de 1626 subieron del 5\% al 10\% los aranceles sobre los restantes productos importados y exportados. Las Cortes de 1645-46 los elevaron hasta un 13\% para el período 1647-5061.

Insuficiente el aumento arancelario para cubrir el subsidio real, las Cortes de 1626 aplicaron un impuesto del 5\% sobre el valor de la producción textil durante los quince años de su duración (1628-42). Como compensación a los gremios textiles, prohibieron importar tejidos extranjeros de lana, seda, oro y plata en Aragón desde 1627. Aquellos fabricados en territorios bajo soberanía hispánica solo podían transitar para su venta en otras regiones. Gremios, comerciantes y municipios demandaron ante las Cortes de 1645-46 un cumplimiento más riguroso de esta ley, eludida continuamente mediante el contrabando; pero la presión de las elites agrarias logró derogar dicha prohibición. En consecuencia, este Parlamento no renovó el impuesto del 5\% tras su expiración ${ }^{62}$.

59. Dormer, D. J., op. cit., pp. 9-14, 23.

60. ADZ, ms. 334, fol. 78r-79r, ms. 445, fo. 341-348; Perdices de Blas, L. y Sánchez Molledo, J. M. (eds.), pp. 206-207.

61. Savall y Dronda, P. y Penén Debesa, S., t. I, pp. 468, 475; t. II, pp. 371-372.

62. Idem, t. I, pp. 453-454. 
JOSÉ ANTONIO MATEOS ROYO

POLÍTICA PÚBLICA Y PROTECCIONISMO CORPORATIVO:

INSTITUCIONES REGIONALES Y GREMIOS TEXTILES EN ARAGÓN DURANTE EL SIGLO XVII

Como revelan las actuaciones legales de la Diputación, la prohibición y los ascensos arancelarios adoptados en 1626 y $1645-46$ propiciaron que los gremios recrudeciesen sus obstáculos al tránsito de mercancías aragonesas y extranjeras, solo atenuados tras rebajarse en 1651 los aranceles de importación y exportación al $10 \%{ }^{63}$. Al elevar los costes de transacción y restringir la competencia exterior, leyes regionales y trabas locales permitieron a los gremios textiles en 1627-45 aumentar el precio de sus manufacturas. La demanda generada por el ejército castellano y la Corte real en Aragón durante la guerra de secesión catalana (164052) contribuyó a mantener estas prácticas.

Si bien la presión del creciente contrabando moderó en 1627-45 el aumento de precios de la producción manufacturera realizada en Zaragoza y las mayores ciudades aragonesas, su calidad disminuyó ${ }^{64}$. La restricción de la competencia por los gremios textiles mejor cohesionados fue más efectiva durante este período en pequeñas ciudades. Como permitían las leyes aprobadas por las Cortes de 1626, los municipios tasaron la producción textil según el valor de las materias primas que requería su fabricación para moderar los fuertes ascensos de precios que los gremios querían imponer ${ }^{65}$. Esta limitación parcial de la competencia continuó perjudicando al consumidor tras derogarse la prohibición de importar textiles extranjeros en 1646. Si en Albarracín los pelaires aún rechazaban en 1669 muchos paños locales por sus defectos, los tejedores lograron en 1671 un permiso municipal para fabricarlos con menor calidad ${ }^{66}$. El municipio de Daroca tasó regularmente la producción textil local hasta 1675 y nombró supervisores de su calidad ocasionalmente durante la segunda mitad del siglo xvir. La creciente introducción de textiles extranjeros realizada en dicha ciudad a fines de esta centuria anuló la necesidad de tasar las manufacturas locales; pero no de vigilar su calidad ${ }^{67}$.

Pese a mantenerse el ascenso arancelario y las trabas en los mercados locales, la derogación de la prohibición de importar textiles extranjeros aprobada por las Cortes en 1646 aceleró la penetración mercantil francesa y el declive industrial aragonés. Los acuerdos comerciales incluidos en la paz de los Pirineos en 1659 agilizaron este proceso al consolidar el libre comercio, residencia y navegación entre Francia y España y aportar mayores garantías jurídicas a los franceses residentes en territorio hispánico, mantenidas en los restantes tratados sellados entre ambos

63. Dormer, op. cit., p. 23; AMZ, Actas municipales, 1675, fols. 60r-61r y ADPZ, ms. 445, fols. $127 \mathrm{v}, 152 \mathrm{r}$.

64. San Vicente Pino, op. cit., t. II, pp. 178-181.

65. Savall y Dronda, P. y Penén Debesa, S., op. cit., t. II, p. 375.

66. Peiró Arroyo, A.: Tiempo de industria. Zaragoza, 2000, p. 163.

67. Mateos Royo, J. A.: Auge... op. cit., pp. 412-413. 
países durante la segunda mitad del siglo $\mathrm{xvII}^{68}$. Al tiempo que aumentaron los obstáculos a la circulación de manufacturas, gremios y municipios reaccionaron reclamando a la Diputación entre 1668 y 1675 la convocatoria de Cortes para restaurar la prohibición de importar textiles extranjeros ${ }^{69}$. Líder de las medidas proteccionistas ante la fuerte presión de sus gremios textiles, Zaragoza prohibió en 1675 introducir tejidos extranjeros de lana, seda, oro y plata en la ciudad, regulación que fue inmediatamente derogada por la Diputación ${ }^{70}$.

Este declive industrial se unió a otros problemas económicos (control comercial francés, despoblación, falta de moneda) que se agravaron en Aragón desde mediados del siglo XVII y forzaron a las instituciones regionales a plantearse reformas. Hijo bastardo del rey Felipe IV, el virrey don Juan José de Austria creó con este fin en 1674 una Junta de Comercio en Zaragoza, formada por representantes de la Diputación y Corte del Justicia de Aragón, los principales oficiales del municipio y consejeros reales ${ }^{71}$. Su gestación abrió un verdadero debate económico, consolidado al lograr don Juan en 1676 que el nuevo rey Carlos II convocase Cortes en Aragón. Centrado este debate en la política comercial, los gremios urbanos reclamaron fuertes medidas proteccionistas frente a las manufacturas francesas con el apoyo municipal.

Durante las Cortes de 1677-78, los intereses gremiales fueron favorecidos por las necesidades fiscales de la monarquía. Al buscarse nuevos impuestos para sufragar un servicio real durante veinte años, nobleza y clero prefirieron mantener estables los aranceles de salida sobre los productos agrarios aragoneses para favorecer su exportación. Reticentes a crear monopolios de venta regionales, las Cortes aprobaron un ascenso arancelario del $10 \%$ al $20 \%$ en los derechos de entrada y salida sobre las restantes mercancías ${ }^{72}$. Otro impuesto del $5 \%$ sobre el valor de la producción textil regional fue aplicado por veinte años, si bien se anuló todo arancel de salida para favorecer su exportación. Como compensación, las Cortes no solo prohibieron importar textiles extranjeros de lana, seda, oro y plata, sino transportarlos por Aragón para venderlos en otros territorios durante este período. Ante el predecible aumento de precio de los textiles aragoneses generado por esta prohibición, decretaron la formación de una Junta municipal por localidad para tasar el precio de manufacturas regionales y extranjeras ${ }^{73}$.

68. Pérez Sarrión, G.: La península comercial. Mercado, redes sociales y Estado en España durante el siglo XVIII. Madrid, 2012, pp. 124-128.

69. DORMER, op. cit., p. 23

70. AMZ, Actas Municipales, 1675, fol. 49v-64r.

71. BN, ms. 9.825 .

72. ADZ, ms. 734, fols. 2557r-2564v.

73. Savall y Dronda, P. y Penén Debesa, S., op. cit., t. II, pp. 400-408. 
JOSÉ ANTONIO MATEOS ROYO

POLÍTICA PÚBLICA Y PROTECCIONISMO CORPORATIVO:

INSTITUCIONES REGIONALES Y GREMIOS TEXTILES EN ARAGÓN DURANTE EL SIGLO XVII

Sin embargo, estas Cortes no aprobaron leyes que diesen prioridad a artesanos, municipios o particulares al adquirir lana en los mercados locales frente a comerciantes extranjeros como solicitaban gremios y arbitristas, ni siquiera ante carestías $^{74}$. Este proceder contrasta con Castilla, donde los fabricantes podían legalmente adquirir estos años a tanteo parte de la producción lanera durante la Edad Moderna y la exportación de lana basta fue prohibida desde 1699, encareciendo sus costes de transacción en el siglo XviII al sacarse de contrabando ${ }^{75}$. Las Cortes aragonesas ni limitaron la exportación de lana ni siquiera aumentaron sus aranceles de salida al 10\% de su valor, como sugirió Antonio Cubero Sebastián a la Junta de Comercio en 1674. El temor de los ganaderos a que cayese el precio de la lana en el mercado regional se unió a los intereses de los exportadores de lana, poco involucrados en la producción textil a diferencia de Castilla ${ }^{76}$, para frenar estas reformas. Las Cortes solo prohibieron exportar seda en bruto para favorecer su fabricación en Aragón ${ }^{77}$.

Estas leyes no revitalizaron la industria textil regional. Afectada por impuestos sobre la producción, perdió calidad y competitividad: la Diputación nombró así entre 1680 y 1684 inspectores para supervisar los telares de los tejedores de lana, lino, cáñamo y estopa en distintas zonas de Aragón al constatar que estos reducían el número de hilos utilizado en sus tejidos para eludir el impuesto sobre su producción ${ }^{78}$. $\mathrm{Al}$ aumentar los costes de transacción, incrementaron el precio de los textiles franceses introducidos de contrabando: algunos comerciantes aragoneses contrarios a la política proteccionista cifraron en 1684 en un $20 \%$ su ascenso en el mercado regional desde $1678^{79}$. Este aumento acarreó a su vez el de los textiles aragoneses. Las tasaciones municipales de precios se vieron impotentes para frenar este proceso.

En previsión de dificultades, las Cortes de 1677-78 dispusieron que una asamblea formada por ocho delegados designados por los cuatro estamentos podría revisar la política económica seis años después de su puesta en práctica. Ante la ineficacia de las medidas proteccionistas, estos delegados y sus consejeros se reunieron en 1684-86 y negociaron con los representantes reales, actuando de facto como un nuevo Parlamento. Esta asamblea derogó el ascenso arancelario y la prohibición de importar y transportar textiles extranjeros aprobados en 167778. El impuesto sobre la producción textil aragonesa fue suprimido; pero su

74. BN, VE, 180-40, 23-23 y 205-40. Estas propuestas pueden consultarse en Perdices de Blas, L. y Sánchez Molledo, J. M. (eds.), op. cit., pp. 143-144, 165-166, 216.

75. García SANZ, A.: "Competitivos en lanas...», op. cit., pp. 404, 407-409.

76. Idem, pp. 428-429.

77. Savall y Dronda, P. y Penén Debesa, S., op. cit., t. II, p. 407.

78. ADZ, ms. 561, fos. 40r-41r, 50r-51v; ms. 575, fols. 23r-24r, 35r-36r, 66v-67r.

79. BN, VE, 28-45. 
JOSÉ ANTONIO MATEOS ROYO

POLÍTICA PÚBLICA Y PROTECCIONISMO CORPORATIVO:

INSTITUCIONES REGIONALES Y GREMIOS TEXTILES EN ARAGÓN DURANTE EL SIGLO XVII

exportación fue gravada con un $5 \%$ de su valor ${ }^{80}$. Este impuesto limitó la venta exterior de tejidos aragoneses, ya lastrada por su prohibición en Navarra y las barreras administrativas creadas en Castilla a fines del siglo XvII ${ }^{81}$. Por razones fiscales, la Diputación desestimó en 1693 su reducción al 3,5\% solicitada por los pelaires de Albarracín para mejorar la competitividad exterior de su producción ${ }^{82}$.

Estas Cortes de 1684-86 intentaron revitalizar la producción manufacturera al garantizar su derecho a venderse en todo Aragón e incluso imitar tejidos fabricados en otros municipios. Como referencia para avalar su calidad y procedencia, las Cortes decidieron seguir recurriendo a la marca del gremio o del municipio en su defecto $^{83}$. Esta decisión fue solo tomada al denunciar los mercaderes de Zaragoza los altos costes que provocaría colocar la marca del fabricante en cada tejido, sobre todo en los producidos en áreas rurales ${ }^{84}$. Si bien el precio de las manufacturas aragonesas y forasteras siguió siendo tasado por Juntas locales, su supervisión gremial fue sometida a mayor control municipal para evitar rechazos abusivos bajo excusa de su mala calidad. Estas disposiciones aportaban un marco legal más favorable al comercio regional de manufacturas domésticas. Los artesanos del cáñamo de Calatayud lograron así en 1694-99 el apoyo de la Diputación mediante su firma «Magna» para vender sus productos en otras ciudades aragonesas cualquier día del año eliminando las trabas de gremios locales ${ }^{85}$. Pese a estos intentos por crear un mercado más dinámico, la Diputación siguió nombrando supervisores para garantizar la calidad de la producción textil en Aragón a fines del siglo XVII ${ }^{86}$.

Esta política económica fue favorecida por la lenta evolución de los mercados locales en Aragón durante el siglo xvir hacia una mayor dispersión en detrimento de las grandes ferias, constatada en otros mercados de la España interior en este período ${ }^{87}$. Conforme estas grandes ferias celebradas durante el siglo Xvi en Huesca, Barbastro y Daroca decayeron durante la segunda mitad del siglo XvII ${ }^{88}$, Zaragoza y bastantes villas lograron en las Cortes de 1645-46 y 1677-78 licencia para celebrar ferias en lugares y períodos del año que no dañaban la celebración de las existentes. Otros municipios obtuvieron permisos del Consejo de Aragón, organismo

80. Savall y Dronda, P. y Penén Debesa, S., op. cit., $t$. I, pp. 531-532.

81. DORMer, op. cit., pp. 26-27.

82. Peiró Arroyo, A.: Tiempo..., op. cit., p. 163.

83. Savall y Dronda, P. y Penén Debesa, S., op. cit., t. I, p. 531.

84. ADZ, ms. 580, fols. 2334r-2335r.

85. Mateos Royo, J. A.: Ange..., op. cit., pp. 413-414.

86. ADZ, ms. 593, fos. 36r-37r; ms. 594, fols. 70r-71v; ms. 601, fols. 54r-v, 122r; ms. 605, fols. $10 \mathrm{r}-11 \mathrm{r}, 87 \mathrm{v}-88 \mathrm{r}$.

87. Yun Casalilla, B.: Sobre la transición al capitalismo en Castilla. Economía y sociedad en Tierra de Campos (1500-1830). Valladolid, 1987, pp. 524-541.

88. Como ejemplo, véase el declive de las ferias de Daroca en Mateos Royo, J. A.: Auge..., op. cit., pp. 395-396. 
JOSÉ ANTONIO MATEOS ROYO

POLÍTICA PÚBLICA Y PROTECCIONISMO CORPORATIVO:

INSTITUCIONES REGIONALES Y GREMIOS TEXTILES EN ARAGÓN DURANTE EL SIGLO XVII

asesor del monarca en Madrid sobre temas legales, políticos y fiscales relativos a los territorios hispánicos de la Corona de Aragón tras recabar informes de su virrey, gobernador y Real Audiencia o supremo tribunal real de Justicia ${ }^{89}$. Muchas nuevas ferias tenían un ámbito comarcal y limitada duración, pero su creación vertebró mejor el mercado interno y facilitó la comercialización de manufacturas y productos agrarios. Se establecieron preferentemente en villas del norte de la región, cuyas rutas comerciales se seguían beneficiando de su cercanía a Francia y la actividad de mercaderes franceses en Aragón.

Expresión de su pérdida de control sobre el mercado local, muchos artesanos adquirían mercancías forasteras más competitivas para revenderlas ante la escasa calidad de su producción ${ }^{90}$. La difusión de estas prácticas durante la segunda mitad del siglo xviI generó serios conflictos con los mercaderes minoristas en las principales ciudades, sobre todo cuando la prohibición de importar textiles extranjeros elevó su precio y desató un fuerte contrabando. Los fabricantes de lana y seda de Zaragoza defendieron así ante las Cortes en 1684 su práctica tradicional de almacenar y vender textiles de elaboración ajena frente a la cofradía de mercaderes de San Joaquín, que intentaba excluir a todo artesano del comercio minorista ${ }^{91}$. Al primar la reventa sobre la mejora de la producción, los propios gremios consolidaron la primacía de las manufacturas extranjeras en el mercado regional durante este período.

\section{El mercado de trabajo: la promoción profesional}

La incapacidad de la producción textil para afrontar tanto la competencia extranjera como la caída de la demanda interna y externa generó fuertes tensiones en el mercado laboral durante el siglo xvir. Durante la centuria anterior, la fuerte expansión de la industria textil en Aragón había facilitado la movilidad laboral e integración profesional de aprendices y oficiales. Necesitados de mano de obra, los gremios textiles urbanos incorporaron a muchos jóvenes aragoneses desplazados desde villas y aldeas del entorno e incluso a numerosos navarros y franceses emigrados a Zaragoza y otras grandes ciudades del norte de Aragón como Barbastro ${ }^{92}$. Por el contrario, durante el siglo xvir restringieron la promoción profesional en

89. La concesión de dos ferias a Zaragoza en 1678 fue incluso aprobada por las Cortes como fuero. Véase Savall y Dronda, P. y Penén Debesa, S., op. cit., t. I, p. 517. Entre las villas que obtuvieron privilegios del Consejo de Aragón para celebrar ferias o ampliar su duración en el siglo XviI se cuentan Casbas en 1626, Bielsa, Naval, Ariza e Hijar entre 1645 y 1648, Biescas, Bolea y Fraga en 1677, Graus en 1681y Monzón en 1699. Véase ACA, CA, legs. 99, 102, 106.

90. Mateos Royo, J. A.: Ange..., op. cit., p. 413.

91. BN, VE, 218-89 y Sánchez Molledo, J. M., op. cit., pp. 185-186.

92. Desportes Bielsa, op. cit., p. 113; Salas Ausens, J. A.: La población..., op. cit., pp. 245-247. 
JOSÉ ANTONIO MATEOS ROYO

POLÍTICA PÚBLICA Y PROTECCIONISMO CORPORATIVO:

INSTITUCIONES REGIONALES Y GREMIOS TEXTILES EN ARAGÓN DURANTE EL SIGLO XVII

beneficio de los hijos y yernos de los maestros para ampliar su control sobre la producción y comercialización local de textiles mediante dos medios esenciales.

Recurso muy común de los gremios en las ciudades españolas ante mercados de trabajo saturados, el primer medio consistía en obstaculizar el acceso de los oficiales a la maestría encareciendo el coste del examen por diversas vías ${ }^{93}$. La cuota abonada al gremio por realizar el examen fue aumentada progresivamente en las décadas finales del siglo xvi y durante la primera mitad del siglo xviI, con especial fuerza en las mayores ciudades y en los oficios que requerían mayor cualificación -véase el ejemplo de Zaragoza en la tabla 2-. Las sumas pagadas a los examinadores y otros oficiales del gremio presentes en este examen crecieron durante el mismo período. Por último, caso de superar el examen, el aspirante debía ofrecer una comida a los miembros del tribunal. Sin embargo, como ya sucedía en Teruel desde principios del siglo xvi y en otras ciudades (Zaragoza, Huesca, Daroca) desde mediados de esta centuria, los hijos o yernos de maestros solo pagaban la mitad de las cuotas de entrada aplicable al resto. Desde principios del siglo xvII, los gremios de Zaragoza ampliaron este privilegio a las cuotas de los examinadores y oficiales gremiales. Un gremio como el de tejedores de seda, que exigía mayor cualificación, rebajó las cuotas de entrada de yernos e hijos de maestros en la capital hasta una quinta parte del precio normal. Gremios de menor cualificación sitos en pequeñas ciudades como los artesanos del cáñamo en Daroca moderaron los derechos de examen debido a la pobreza de sus miembros. Por tanto, a mayor cualificación profesional y presión del mercado laboral, mayor discriminación a favor de los familiares de los maestros. A semejanza de otras ciudades de la Corona de Aragón como Valencia y Mallorca, los gremios de Teruel discriminaron también según la procedencia de los aspirantes. Unieron a estos ascensos su práctica habitual desde principios del siglo xvi de cobrar mayores cuotas de entrada si el aspirante no era vecino ni aragonés para dificultar la incorporación de inmigrantes ${ }^{94}$.

Estas reformas alteraron el funcionamiento del mercado de trabajo regional. Sobre todo en Zaragoza, la promoción profesional fue dificultada por el aumento de los costes de examen hasta 1650 y su inadecuación al descenso general de los precios durante la segunda mitad del siglo Xvir. Estos obstáculos provocaron una

93. Como ejemplos, Deyá Bauza, M. J.: La manufactura de la llana a la Mallorca Moderna (segles XVI-XVII). Mallorca, 1998, pp. 20-22, 51-54, 66-67; Franch BenAVENT, R.: «El artesanado sedero valenciano en el siglo XVII», en ARANDA PÉrez, F. J. (coord.): La declinación de la monarquía bispánica en el siglo XVII. Cuenca, 2004, pp. 514-517. Al resultar en Madrid los mercados de trabajo más abiertos, los costes fueron menores. Véase Zofío Llorente, J. C.: Gremios y artesanos en Madrid, 1550-1650: la sociedad del trabajo en una sociedad cortesana preindustrial. Madrid, 2005, pp. 313-316, 322-328 y Nieto SÁnchez, J. A.: Artesanos y mercaderes. Una historia social y económica del trabajo en Madrid, 1450-1850. Madrid, 2006, p. 208.

94. Mateos Royo, J. A.: Auge..., op. cit., p. 415; San Vicente Pino, t. II, p. 17, 79, 97, 163-164; Vega y Luque, op. cit., Teruel, 54, 1975, pp. 32, 44 y Teruel, 77-78, 1987, pp. 153-154, 212-213. 
JOSÉ ANTONIO MATEOS ROYO

POLÍTICA PÚBLICA Y PROTECCIONISMO CORPORATIVO:

INSTITUCIONES REGIONALES Y GREMIOS TEXTILES EN ARAGÓN DURANTE EL SIGLO XVII

creciente migración de artesanos en Aragón: los pelaires de Teruel ya indicaron en sus estatutos en 1622 que «muchos oficiales llegaban desde tierras alejadas e incluso reinos extranjeros a la ciudad», por lo que reservaron la maestría para los aragoneses. Al elevar cada gremio los costes totales de examen en función del aumento temporal del número de aspirantes, su cuantía variaba entre ciudades sin relación con la cualificación o ganancias del oficio. Durante la década de 1630 un sastre de Huesca pagaba un $163 \%$ más que en Teruel mientras un tejedor de Zaragoza solo un $81,65 \%$. Al mantener estos costes cuando las solicitudes descendían, los gremios perpetuaron estos desajustes que dificultaron una mejor redistribución regional de la mano de obra artesanal, pese a su movilidad ${ }^{95}$.

Un segundo medio consistía en excluir del mercado de trabajo a miembros del gremio en peor situación económica. Iniciativas como las de los tejedores de Teruel, quienes decidieron en 1622 fabricar telares para alquilarlos a maestros empobrecidos, fueron raras ante las carencias de capital de los gremios textiles $^{96}$. Con mayor frecuencia, estos gremios dictaron estatutos para impedir que oficiales no examinados y maestros empobrecidos que carecían de tienda propia pudiesen vender su producción en el mercado local. Estas medidas restrictivas ahondaban en el proceso de diferenciación social entre artesanos ya iniciado por la expansión de la industria textil en Aragón durante el siglo xvi. Las modificaciones del proceso productivo impuestas por el aumento de la demanda provocaron así en Zaragoza que los tejedores de lana fueran convirtiéndose en meros asalariados de los pelaires que controlaban este proceso por su mayor capacidad financiera ${ }^{97}$. Proceso constatado con especial nitidez en las ciudades de la Corona de Aragón, donde una elite de artesanos-fabricantes desconocida en Castilla retuvo total o parcialmente el control de la producción textil urbana en la Edad Moderna, la contracción del mercado de trabajo durante el siglo xviI agudizó la subordinación y proletarización de muchos artesanos frente a otros dentro del gremio ${ }^{98}$.

95. Arco y Garay, R. de: Antiguos gremios de Huesca. Ordenaciones y documentos, Zaragoza, 1911, p. 60; Vega y LuQue, op. cit., Teruel, 54, 1975, pp. 44, Teruel,77-78, 1987, pp. 166-167; SAN Vicente Pino, op. cit., t. II, p. 121.

96. Vega y LuQue, op. cit., Teruel, 54, 1975, p. 43.

97. Desportes Bielsa, op. cit., pp. 181-184.

98. Como ejemplos, véase Vázquez de Prada, V. y Molas Ribalta, P.: «la industria llanera a Barcelona. Segles XVI-XVII» en Molas Ribalta, P. (coord.): Economía i societat al segle XVIII. Barcelona, 1975, p. 153; Díez Rodríguez, F.: Viles y mecánicos. Trabajo y sociedad en la Valencia preindustrial, Valencia, 1990, pp. 89-94; Torras Elías, J.: «Gremio, familia y cambio económico. Pelaires y tejedores en Igualada, 1695-1765», Revista de Historia Industrial, 2, 1992, pp. 16-19; Torró GIL, Ll.: Abans de la indústria. Alcoi als inicis del sis-cents. Alicante, 1994, p. 184; DeYá BaUza, M. J.: La manufactura..., op .cit., pp. 50, 55-56, 67. La propia normativa gremial aprobada por la monarquía obstaculizó el surgimiento de los artesanos-fabricantes en Castilla durante el siglo xvi. Véase GARCía SAnz, A.: Desarrollo y crisis del Antiguo Régimen en Castilla la Vieja. Economía y sociedad en tierras 
JOSÉ ANTONIO MATEOS ROYO

POLÍTICA PÚBLICA Y PROTECCIONISMO CORPORATIVO:

INSTITUCIONES REGIONALES Y GREMIOS TEXTILES EN ARAGÓN DURANTE EL SIGLO XVII

En esta línea, otros gremios textiles establecieron que los oficiales no podían independizarse de su maestro antes de haber saldado sus deudas con este ${ }^{99}$. Dicha medida buscaba garantizar al maestro la recuperación del coste de formación de los oficiales, quienes intentaban establecerse por su cuenta ante la imposibilidad de sufragar el examen de maestría. Este problema alcanzó especial gravedad en Zaragoza ya en la segunda mitad del siglo xvi: al tiempo que su acceso a la maestría se dificultaba por el encarecimiento del examen, los oficiales veían que los maestros preferían contratar varios aprendices -las ordenanzas gremiales no les imponían un número máximo- que darles trabajo para reducir costes de producción o forzar a los oficiales a rebajar sus salarios. Ante su rápida proletarización, los oficiales textiles intentaron crear sus propias asociaciones, surgidas en fechas más tempranas que en otras ciudades españolas ${ }^{100}$. Los primeros intentos fracasaron: si el municipio prohibió a los oficiales sastres formar en 1556 su propia cofradía, los maestros tejedores integraron en 1581 a sus oficiales en la suya para frustrar una tentativa similar. Fruto de sus crecientes dificultades, tanto los tejedores de lino y lana como los pelaires crearon en 1601 y 1606 las asociaciones de oficiales más antiguas de Zaragoza para defender sus derechos. Oficiales pelaires y tejedores incluso solicitaron al municipio en 1644 y 1653 que obligase a todo oficial a ingresar en la fraternidad; pero la oposición de los maestros les privó de su apoyo ${ }^{101}$.

En ciudades de la Corona de Aragón como Valencia y Mallorca, esta creciente desigualdad en el mercado de trabajo forzó a instituciones públicas como la Real Audiencia, el virrey y los municipios a intervenir para flexibilizar las trabas gremiales y así mejorar la producción local o evitar posibles conflictos sociales ${ }^{102}$. Estas actuaciones recayeron en Aragón sobre los municipios y ganaron importancia desde el segundo cuarto del siglo xvir, cuando las leyes aprobadas por las Cortes de 1626 y 1645-46 propiciaron ascensos de precios y descensos de calidad en los textiles aragoneses.

de Segovia de 1500 a 1814. Madrid, 1986, pp. 211-214 y ForTea Pérez, J. I.: Córdoba en el siglo XVI: las bases demográficas y económicas de una expansión urbana. Córdoba, 1981, p. 337.

99. Mateos Royo, J. A.: Auge..., op. cit., p. 417.

100. Desportes Bielsa, op. cit., pp. 187-188. Otro caso temprano, las primeras asociaciones de oficiales artesanos en Madrid datan de finales del siglo xvi. Véase Nieto Sánchez, J. A.: «Asociación y conflicto laboral en el Madrid del siglo xviII», en López Barahona, V. y Nieto Sánchez, J. A. (eds.): El trabajo en la encrucijada. Artesanos urbanos en la Europa de la Edad Moderna. Madrid, 1996, pp. 265-267.

101. Ibidem; Redondo Veintemillas, op. cit., p. 88; Peiró Arroyo, A.: Jornaleros..., op. cit., pp. 113-114, 132.

102. Deyá Bauza, M. J.: La manufactura..., op .cit., pp. 20-21, 54, 66; Baixauli Juan, I. A.: Els artesans de la Valenciá del segle XVII. Capitols del oficis y col-legis. Valencia, 2001. 
JOSÉ ANTONIO MATEOS ROYO

POLÍTICA PÚBLICA Y PROTECCIONISMO CORPORATIVO:

INSTITUCIONES REGIONALES Y GREMIOS TEXTILES EN ARAGÓN DURANTE EL SIGLO XVII

TABla 2. Derechos de examen pagados a gremios textiles de Zaragoza

(primera mitad del siglo XVII)

-en sueldos-

\begin{tabular}{|c|c|c|c|c|c|}
\hline \multicolumn{2}{|c|}{ Tejedores } & \multicolumn{2}{c|}{ Tejedores e hiladores } & \multicolumn{2}{c|}{ Fabricantes de sacos } \\
\hline Año & e hiladores de seda & Año & de lana y lino & Año & de fibras vegetales \\
\hline 1601 & 160 sueldos & 1607 & 240 sueldos & 1620 & 200 sueldos \\
\hline 1617 & 200 sueldos & 1629 & 320 sueldos & 1633 & 240 sueldos \\
\hline 1633 & 300 sueldos & 1652 & 480 sueldos & 1656 & 300 sueldos \\
\hline 1641 & 600 sueldos & 1653 & 440 sueldos & & \\
\hline & & 1654 & 480 sueldos & & \\
\hline
\end{tabular}

Fuente: elaboración propia a partir de Redondo Veintemillas, G., op .cit., pp. 88, 110, 272; SAN Vicente Pino, op. cit., t. II, pp. 17, 79, 97, 163-164 y Peiró Arroyo, A.:Jornaleros..., op. cit., p. 132.

Nota: el sueldo era una unidad de cuenta utilizada en Aragón durante las Edades Media y Moderna. Tras la adopción del peso y ley castellanos en todas las emisiones de plata desde 1519, un sueldo equivalía a medio real, la principal moneda de plata acuñada en Aragón durante los siglos XVI y xvII.

En primer lugar, los municipios utilizaron su patronazgo sobre los gremios para derogar algunos estatutos gremiales que entorpecían excesivamente la promoción profesional. Si bien aprobaron frecuentemente ascensos de las cuotas de examen que beneficiaban a hijos y yernos de maestros, redujeron en ocasiones tasas abusivas percibidas por examinadores y oficiales del gremio o suprimieron la exigencia de que el candidato aprobado les ofreciera una comida tras aprobar el examen ${ }^{103}$. Todo aspirante descontento con el resultado del examen podía solicitar ser evaluado por artesanos nombrados por el municipio. Zaragoza incluso designó en 1672 sus propios evaluadores al constatar que el rigor de los examinadores de los gremios artesanales privaba sistemáticamente a la ciudad de mano de obra competente ${ }^{104}$.

En segundo término, los municipios podían permitir a artesanos forasteros residir y trabajar sin pasar el examen de maestría. Muchas pequeñas ciudades obraban así si estos artesanos practicaban oficios con débil organización gremial para ampliar la producción local: en Daroca el municipio eximió a tejedores forasteros casados en esta ciudad de realizar el examen en varias ocasiones (1627, $1645,1662)$ hasta consolidarse su gremio en 1673. Zaragoza utilizó estos permisos desde 1626 para forzar a gremios bien constituidos a mejorar su producción

103. San Vicente Pino, op. cit., t. II, pp. 181-182.

104. Redondo Veintemillas, G., op.cit., p. 152. 
JOSÉ ANTONIO MATEOS ROYO

POLÍTICA PÚBLICA Y PROTECCIONISMO CORPORATIVO:

INSTITUCIONES REGIONALES Y GREMIOS TEXTILES EN ARAGÓN DURANTE EL SIGLO XVII

hasta 1695 cuando los revocó tras considerar que un mayor control gremial era indispensable para garantizar su calidad ${ }^{105}$.

En tercer lugar, los municipios facilitaron la incorporación de oficiales y maestros empobrecidos a la producción y comercialización local frente a las restricciones de los gremios, aprovechando su control incompleto sobre el mercado urbano de trabajo. Durante la primera mitad del siglo xviI, esta intervención fue más eficaz en oficios dedicados a trabajar fibras vegetales por su débil organización gremial hasta principios de esta centuria. El municipio de Daroca permitió en 1630 a los oficiales artesanos del cáñamo vender su producción en sus casas, o utilizar casas o tiendas de amigos suyos. El gremio de artesanos del lino y cáñamo de Zaragoza aceptó en sus Ordenanzas en 1633 el ingreso de tenderos que vendían sus productos sin pasar examen; pero pagando la cuota de entrada. Como ya actuaban los oficiales sastres en 1595 y 1605, el municipio de Huesca declaró en 1643 que todos los oficiales artesanos de la ciudad podían trabajar y vender en sus casas sin necesidad de disponer de taller propio para facilitarles independizarse de sus maestros. En 1674 el municipio de Daroca permitió a los maestros sastres trabajar en casas de particulares por un salario diario fijo ${ }^{106}$.

Por último, recurso propio de Aragón, los municipios aprovecharon la continua demanda de levas militares por la monarquía española para aliviar las tensiones del mercado laboral. Estallada la guerra entre España y Francia en 1635, Zaragoza prometió en 1638 a todo oficial artesano que sirviese varios meses en la compañía levantada por la ciudad el ejercicio de su oficio sin pasar el examen. Otros municipios -Huesca, Barbastro, Calatayud, Daroca- siguieron su ejemplo al rebelarse Cataluña frente a la monarquía hispánica en 1640. Pese a las quejas de los gremios, su concesión fue mantenida durante las sucesivas guerras libradas entre España y Francia durante el siglo XviI (1635-59, 1667-68, 1673-78, 168384, 1689-97) y alcanzó especial regularidad entre 1641 y 1652 ante la invasión de Aragón por el ejército francés en 1641-43 y la posterior conquista de Cataluña por las tropas españolas ${ }^{107}$. Tras acusar en 1672 a los gremios de fomentar la huida de muchos oficiales artesanos a pequeñas ciudades o aldeas con sus cuotas de examen, Zaragoza concedió excepcionalmente 144 permisos entre 1675 y 1680, 66 de estos a artesanos textiles. Como Zaragoza de nuevo en 1686, Huesca en 1684

105. Idem, pp. 151-154; Mateos Royo, J. A.: Auge..., op. cit., p. 416.

106. Idem, pp. 89-90; Arco y Garay, R. de: Antiguos gremios..., op. cit., pp. 52-56 y «Estatutos dictados por el Consejo general de la ciudad de Huesca», Linajes de Aragón, VI, 1915, p. 139; Mateos Royo, J. A.: Auge..., op. cit., p. 417.

107. Sanz Camañes, P.: Política, hacienda y milicia en el Aragón de los últimos Austrias entre 1640 y 1680. Zaragoza, 1997, pp. 154, 191, 221, 294. 
y Albarracín en 1694 otorgaron licencias similares. Consideradas propiedad del soldado, eran incluso vendidas o transmitidas en herencia ${ }^{108}$.

Pese a los esfuerzos municipales, los obstáculos gremiales a la promoción profesional persistieron y propiciaron una fuerte movilidad laboral entre los artesanos durante la segunda mitad del siglo xvir. Principales perjudicadas por el declive industrial, esta situación afectó a las ciudades con mayor tradición textil ${ }^{109}$. Oficiales y maestros empobrecidos emigraron buscando ciudades y villas donde gremios y municipios pusiesen menos obstáculos a su integración profesional. Ante esta realidad, el estatuto municipal de Zaragoza que prohibía en 1675 introducir tejidos extranjeros de lana y seda disponía que cualquier oficial recién llegado fuese admitido en estos gremios textiles sin pagar derechos de ingreso hasta pasados tres años de residencia ${ }^{110}$. La fuerte precariedad laboral provocó que el debate económico generado en Aragón entre 1674 y 1686 incluyese opiniones que defendían reducir las trabas de acceso a la maestría para consolidar un artesanado mejor formado y más competitivo.

Como hizo Zaragoza en 1675, esta posición fue asumida por firmes partidarios del proteccionismo que triunfó en las Cortes de 1677-78. Consideraron que los gremios podían realizar esta concesión al reducirse su competencia exterior por la prohibición de importar manufacturas extranjeras y el ascenso arancelario sobre la importación de otros productos. Los mercaderes aragoneses defendieron principalmente la atracción de artesanos extranjeros para revitalizar la industria y población. Antonio Cubero Sebastián propuso en 1677 y 1678 admitir en los gremios a los maestros extranjeros ya examinados sin pagar cuota de entrada ni derechos de examen ${ }^{111}$. Junto a esta medida, los mercaderes de Zaragoza recomendaron en 1677 permitir a los artesanos franceses no examinados pagar solo la mitad de los costes del examen, si lo realizaban durante los tres primeros años de su llegada ${ }^{112}$. Otros arbitristas abogaron por reducir los costes de examen de aragoneses y extranjeros a una suma modesta y dar facultad a los poderes públicos para volver a evaluar al examinado tras ser este rechazado por los gremios ${ }^{113}$. Una Junta asesora formada por ocho representantes de cada estamento recomendó en

108. Redondo Veintemillas, G., op .cit., pp. 293-294; Peiró Arroyo, A.: Jornaleros..., op. cit., pp. 86-87; Mateos Royo, J. A.: Auge..., op. cit., pp. 407, 416.

109. ADZ, ms., 523, fols. 215-422.

110. AMZ, Actas Municipales, 1675, fol. 56r-v.

111. BN, VE, 205-40, 25-10; Perdices de Blas, L. y Sánchez Molledo, J. M. (eds.), op. cit., pp. 216-217, 257.

112. BN, VE, 168-1, 28-40, 209-92.

113. BN, VE, 209-60. 
JOSÉ ANTONIO MATEOS ROYO

POLÍTICA PÚBLICA Y PROTECCIONISMO CORPORATIVO:

INSTITUCIONES REGIONALES Y GREMIOS TEXTILES EN ARAGÓN DURANTE EL SIGLO XVII

1677 a las Cortes suprimir los exámenes de maestría para facilitar la promoción de oficiales; pero mantener los gremios para organizar el trabajo artesanal ${ }^{114}$.

Como respuesta, los 42 gremios de Zaragoza solicitaron al rey y las Cortes en 1678 mantener los exámenes. Alegaron que su supresión impediría formar mano de obra cualificada y asegurar una producción homogénea y regular en las ciudades. Generaría un exceso de oferta de manufacturas de baja calidad realizadas por artesanos extranjeros. La rápida adquisición del derecho a establecer tiendas por muchos oficiales aragoneses deprimiría los precios del mercado. En consecuencia, muchos maestros rechazarían emplear aprendices y oficiales para evitar una saturación del mercado laboral y de mercancías que acarrearía la ruina de todo el artesanado. Por último, los gremios no podrían mantenerse solo con las miajas o aportaciones anuales de los miembros, como recomendaba la Junta, sin preservar las cuotas de examen ${ }^{115}$.

Al discutir los estamentos la propuesta de la Junta, el clero y la alta y baja nobleza se mostraron favorables a suprimir los exámenes de maestría en Aragón. Sin embargo, los ciudadanos se opusieron, conscientes de la necesidad de la colaboración gremial para organizar y controlar la producción y comercialización local de manufacturas ${ }^{116}$. La creación de impuestos sobre la producción textil y exportación de otras mercancías artesanales para completar el servicio real aseguraron la continuidad de los exámenes. Sin estos ingresos, los gremios solo podrían afrontar los consiguientes mayores costes de fabricación a costa de encarecer excesivamente la venta de sus productos.

Pese a preservar los exámenes, las Cortes de 1677-78 fijaron la cuantía máxima del derecho a examen y pagos a examinadores en todo Aragón tras agrupar a los oficios en dos categorías según grado de cualificación. La primera requería pagar hasta 300 sueldos en Zaragoza y 180 sueldos en las restantes localidades como costes totales del examen. Para la segunda, estas cantidades suponían 150 y 120 sueldos. Oficiales y maestros forasteros tenían así un asidero legal para protestar contra peticiones excesivas de los gremios. Este Parlamento confirmó a todo artesano la posibilidad de recurrir ante el municipio si consideraba injusto el resultado de su examen ${ }^{117}$.

114. BN, VE, 28-77; Sánchez Molledo, op. cit., pp. 72-73.

115. BN, VE, 209-137. Su trascripción, en Perdices de Blas, L. y Sánchez Molledo, J. M. (eds.), op. cit., pp. 323-331.

116. ADZ, ms. 733, fol. 2045r-2064v.

117. Savall y Dronda P. y Penén Debesa, S., op. cit., t. II, pp. 408-409. El salario diario de un peón agrícola osciló en las ciudades aragonesas entre tres y cuatro sueldos en el período 1640-75. Véase Salas Ausens J. A.: La población..., op. cit., pp. 304-305; Mateos Royo, J. A.: Ange..., op. cit., pp. 373-374. 
El debate sobre política comercial efectuado en las Cortes de 1684-86 ante el fracaso de las medidas proteccionistas no contempló suprimir los exámenes de maestría. Los defensores del libre comercio no consideraron posible que los gremios subsistiesen sin las cuotas de examen si -como defendían- desaparecía la prohibición de importar o transitar textiles extranjeros y bajaban los aranceles de importación sobre los productos artesanales. Su principal campeón, Diego José Dormer criticó sin paliativos en 1684 en sus Discursos históricos políticos la escasa preparación del artesanado aragonés. Como soluciones, Dormer propuso incentivar el trabajo de los artesanos nativos y procedentes de la restante Corona de Aragón, Castilla y Navarra facilitándoles el acceso a honores y cargos municipales. Recomendó favorecer la llegada de artesanos extranjeros a Aragón mediante la proporción de ayudas de viaje y facilidades para adquirir materias primas y vender su producción mientras instalaban sus fábricas ${ }^{118}$.

Conscientes de la fuerte migración laboral generada por el declive artesanal en Aragón ${ }^{119}$, las Cortes de 1684-86 intentaron facilitar la incorporación de artesanos forasteros -extranjeros y naturales-a los gremios. Se les permitió examinarse sin presentar pruebas de haber trabajado previamente como aprendices y oficiales los años exigidos, así como se les redujo a la mitad los costes de examen fijados en 1677-78. Se prohibió que los examinadores exigiesen obras excesivamente laboriosas a los aspirantes. Caso de ser aceptado el forastero en un gremio, si decidía cualificarse en otro oficio integrado en este, dichos costes serían sólo una sexta parte ${ }^{120}$.

La incidencia de esta legislación sobre la producción textil resulta difícil de medir. Pieza clave, las tasaciones de derechos de examen allanaban el acceso a la maestría a artesanos con pocos recursos al reducir los costes fijados por el gremio; pero les acarreaban dificultades con este durante el examen o tras su superación. La actitud de los artesanos que trabajaban el cáñamo y lino en Zaragoza es significativa. La tasación aprobada en 1678 rebajó a una tercera parte los derechos de examen y fue reclamada inmediatamente por oficiales forasteros. Los hijos y yernos de los maestros prefirieron seguir pagando la mitad de la cuota tradicional para ganarse el apoyo del gremio. De hecho, su proporción en el total de maestros admitidos creció en las décadas siguientes a la instauración de dicha tasación. Entre los artesanos del cáñamo, pasó desde un $24 \%$ en $1681-90$ a un 32,4\% en $1691-1700$ y un $48,1 \%$ en $1701-10$. Entre los artesanos del lino, desde un $12,5 \%$ a un $23,8 \%$ y a un $40 \%$ en estos períodos ${ }^{121}$. Estos porcentajes serían superiores en otros gremios

118. DORMER, op. cit., pp. 33-34, 40-43.

119. Sánchez Molledo, op. cit., pp. 180-182.

120. Savall y Dronda P. y Penén Debesa, S., op. cit., t. I, p. 530.

121. Redondo Veintemillas, pp. 111, 269-271; Peiró Arroyo, A.: Jornaleros..., op. cit., pp. 56-57. 
JOSÉ ANTONIO MATEOS ROYO

POLÍTICA PÚBLICA Y PROTECCIONISMO CORPORATIVO:

INSTITUCIONES REGIONALES Y GREMIOS TEXTILES EN ARAGÓN DURANTE EL SIGLO XVII

ya conformados en la Baja Edad Media como los de la lana y seda, que requerían mayor formación del aspirante pero cuya producción era menos competitiva en el mercado regional. Al contar con menos miembros en las pequeñas ciudades, los gremios se resistieron más a reducir sus cuotas. Pese a rebajar solo un $20 \%$ los derechos de examen, los artesanos del cáñamo de Daroca solo aplicaron hasta 1691 la tasación establecida por las Cortes de $1678^{122}$.

\section{Conclusiones}

Las conclusiones del estudio asumen que los gremios influyeron en distinto grado en la economía europea según áreas geográficas y períodos históricos durante la Edad Moderna. Su desempeño en el caso aragonés refleja una fuerte adaptación a cambiantes factores económicos e institucionales, según sostuvieron Kaplan, Farr y Sonenscher en sus estudios sobre ciudades francesas. Esta flexibilidad facilitaría la supervivencia de los gremios; pero limitaría sus posibilidades de incidir con autonomía y regularidad en esta economía regional en el largo plazo. Moderado su control del mercado por las instituciones públicas para reducir los costes de transacción, durante el siglo xvi los gremios textiles aragoneses gestionaron abundantes recursos naturales y humanos con eficiencia y adoptaron innovaciones técnicas como sostuvo Epstein. Ante un contexto económico recesivo, aplicaron durante el siglo XviI las estrategias rentistas y restrictivas de la competencia descritas por Ogilvie al regular los mercados locales de mercancías y trabajo. Conscientes de sus consecuencias económicas perjudiciales, las instituciones públicas toleraron estas estrategias con limitaciones tanto por motivos fiscales al servicio de las elites agrarias como por la necesidad de organizar la producción y el mercado artesanales percibida por las oligarquías urbanas.

Las circunstancias económicas que lastraron la actividad de los gremios textiles en Aragón coinciden con las que ocasionaron la decadencia de la producción textil urbana en España durante el siglo xviI: caída de la demanda por el descenso de la población y mayor presión fiscal, declive de la burguesía mercantil, descenso de la inversión productiva, escasez y encarecimiento del crédito... La falta de reconocimiento social de las actividades comerciales y fabriles alejó toda posibilidad de que la industria textil recibiese inversiones de las elites rentistas. Estas circunstancias mermaron los beneficios de los artesanos-fabricantes y favorecieron la penetración del capital mercantil en sectores textiles, sobre todo en aquellos que requerían menor cualificación. Ante su estancamiento técnico, la producción textil gremial perdió competitividad frente a las manufacturas francesas. A semejanza de iniciativas similares tomadas en España bajo Carlos II, las instituciones

122. Mateos Royo, J. A.: Ange..., op. cit., p. 415. 
JOSÉ ANTONIO MATEOS ROYO

POLÍTICA PÚBLICA Y PROTECCIONISMO CORPORATIVO:

INSTITUCIONES REGIONALES Y GREMIOS TEXTILES EN ARAGÓN DURANTE EL SIGLO XVII

públicas aragonesas intentaron atraer empresarios extranjeros que aportasen esta renovación técnica, pese a la oposición de los gremios.

Como sucedía en las restantes ciudades españolas, los gremios aragoneses restringieron la competencia exterior en los mercados locales ante el declive de su producción. La especificidad aragonesa radica en su adecuación a la política comercial regional aprobada en Cortes, ganando intensidad en aquellos períodos en que rigieron fuertes políticas proteccionistas. Más eficiente en pequeñas que en grandes ciudades, esta estrategia propició una menor calidad y alzas de precios de las manufacturas aragonesas, aumentando los costes de transacción. Contó con el apoyo municipal en defensa del artesanado local; pero sufrió la fuerte oposición de la Diputación para garantizar el libre tránsito de manufacturas que interesaba a las elites agrarias. Beneficiada por la moderación del proteccionismo y ampliación del sistema ferial, la consolidación de las manufacturas francesas en el mercado regional tras 1650 resultó decisiva para reducir estas alzas de precios. Pese a decaer los controles de calidad de los gremios sobre su producción, las Cortes de 1684-86 mantuvieron su marca como medio más eficiente y barato que la del fabricante para valorar los tejidos en los mercados locales.

Práctica habitual en las ciudades españolas al saturarse el mercado laboral, los gremios aragoneses erigieron ya durante la primera mitad del siglo xviI crecientes barreras a la promoción y práctica profesional en detrimento de los aspirantes a la maestría no emparentados con maestros del gremio y aquellos de sus miembros más empobrecidos. Aplicadas con especial fuerza en grandes ciudades, restaron eficiencia al funcionamiento del mercado laboral pese a la creciente movilidad de artesanos en busca de trabajo, sobre todo desde 1650. Proceso especialmente marcado en la Corona de Aragón donde un sector de artesanos-fabricantes retuvo total o parcialmente el control de la producción textil urbana durante la Edad Moderna, estas estrategias propiciaron una mayor desigualdad económica y proletarización dentro del gremio. Política pública practicada en esta Corona, los municipios aragoneses intentaron flexibilizar el mercado laboral para mejorar la producción textil y aliviar tensiones sociales. Las mismas Cortes fijaron en 1677-78 el coste de los exámenes para facilitar un acceso homogéneo a la maestría en Aragón y aprobaron en 1684-86 mayores garantías en el examen y reducciones de su coste para los artesanos forasteros. Esta política pública regional solo moderó parcialmente las trabas gremiales a la promoción profesional. 
JOSÉ ANTONIO MATEOS ROYO

POLÍTICA PÚBLICA Y PROTECCIONISMO CORPORATIVO:

INSTITUCIONES REGIONALES Y GREMIOS TEXTILES EN ARAGÓN DURANTE EL SIGLO XVII

\section{BibliografíA}

Abadía Irache, A.: La enajenación de rentas señoriales en el reino de Aragón. Zaragoza, 1998.

Arco y Garay, R. de: Antiguos gremios de Huesca. Ordenaciones y documento. Zaragoza, 1911.

Arco y Garay, R. de: «Estatutos dictados por el Consejo general de la ciudad de Huesca», Linajes de Aragón, VI, 1915, pp. 128-139.

Asso, I. de: Historia de la economía política de Aragón. Zaragoza, 1983 (facsímil del original impreso de 1798).

Baixauli Juan, I. A.: Els artesans de la Valenciá del segle XviI. Capitols del oficis y col-legis. Valencia, 2001.

CASEY, J.: El reino de Valencia en el siglo XVII. Madrid, 1983.

Chacón Jiménez, F.: «El artesanado y la economía urbana en el siglo XviI», en Jover Zamora, J. M. (dir.): La crisis del siglo XVII. Historia de España Menéndez Pidal, t. XXIII. Madrid, 1989, pp. 237-326.

Desportes Bielsa, P.: La industria textil en Zaragoza en el siglo XVI. Zaragoza, 1999.

Díez Rodríguez, F.: Viles y mecánicos. Trabajo y sociedad en la Valencia preindustrial. Valencia, 1990.

Deyá Bauza, M. J.: La manufactura de la llana a la Mallorca Moderna (segles XVI-XVII). Mallorca, 1998.

Dormer, D. J.: Discursos históricos-políticos. Zaragoza, 1989 (facsímil del original impreso en 1684).

Duran Pujol, M.: «Oferta y consumo de tejidos en Cataluña en la segunda mitad del siglo XVII», Revista de Historia Económica, XXI, 4, 2003, pp. 61-88.

Epstein, S. R.: «Craft Guilds, Apprenticeship, and Technological Change in Preindustrial Europe», The Journal of Economic History, 58, 3, 1998, pp. 684-713.

Epstein, S. R.: Freedom and Growth: the Rise of States and Markets in Europe, 13001750. Londres, 2000.

Epstein, S. R. y Prak, M. (eds.): Guilds, Innovation and the European Economy, 14001800. Cambridge, 2008.

FARR, J.: Hands of Honor: Artisans and their world in Dijon, 1550-1650. Nueva York, 1988

FARR, J.: «On the Shop Floor: Guilds, Artisans and the European Market Economy, 13501750», Journal of Early Modern History, 1, 1997, pp. 24-54.

Fortea PÉrez, J. I.: Córdoba en el siglo XVI: las bases demográficas y económicas de una expansión urbana. Córdoba, 1981.

Franch Benavent, R.: «El artesanado sedero valenciano en el siglo XviI», en Aranda PÉrez, F. J. (coord.): La declinación de la monarquía hispánica en el siglo XVII. Cuenca, 2004, pp. 511-524.

García Sanz, A.: Desarrollo y crisis del Antiguo Régimen en Castilla la Vieja. Economía y sociedad en tierras de Segovia de 1500 a 1814. Madrid, 1986. 
JOSÉ ANTONIO MATEOS ROYO

POLÍTICA PÚBLICA Y PROTECCIONISMO CORPORATIVO:

INSTITUCIONES REGIONALES Y GREMIOS TEXTILES EN ARAGÓN DURANTE EL SIGLO XVII

García SAnz, A.: «Competitivos en lanas, pero no en paños: lana para la exportación y lana para los telares nacionales en la España del Antiguo Régimen», Revista de Historia Económica, XII, 2, 1994, pp. 397-434.

Gómez Zorraquino, J. I.: La burguesía mercantil en el Aragón de los siglos XVI y XVII (1516-1652). Zaragoza, 1987.

Gómez Zorraquino, J. I.: Zaragoza y el capital comercial. La burguesía mercantil en el Aragón de la segunda mitad del siglo XVII. Zaragoza, 1987.

Gómez Zorraquino, J. I.: «Del concejo foral al ayuntamiento borbónico. La mudanza en el poder municipal (siglos XVI-XVIII)», en El municipio en Aragón. 25 siglos de Historia. Zaragoza, 2004, pp. 99-132.

GonZÁlez Arce, J. D.: «Los gremios contra la construcción del libre mercado. La industria textil de Segovia a fines del siglo Xv y principios del siglo XVI», Revista de Historia Industrial, XIX, 42, 2010, pp. 15-42.

González Enciso, A.: «Les facettes de la pluriactivité dans les industries rurales de l’Espagne moderne», en Minovez, J. M., Verna, C y Hilaire-Pérez, L. (dirs.): Les industries rurales dans l'Europe médiévale et moderne. Toulouse, 2013, pp. 203-221.

Hernández García, R.: La industria textil en Palencia durante los siglos XVI y XVII. Valladolid, 2007.

Kamen, H.: La España de Carlos II. Barcelona, 1981.

Kaplan, S. L.: «Réflexions sur la police du monde du travail», Revue historique, 261, 1979, pp. 17-77.

Kaplan, S. L.: La fin des corporations. París, 2001.

Marcos Martín, A.: España en los siglos XVI, XVII y XVIII. Economía y sociedad. Barcelona, 2000.

Mateos Royo, J. A.: Auge y decadencia de un municipio aragonés: el concejo de Daroca en los siglos XVI y XVII. Daroca 1997.

Mateos Royo, J. A.: «Propios, arbitrios y comunales. la hacienda municipal en el reino de Aragón durante los siglos XVI y XVII», Revista de Historia Económica, XXI, 3, 2003, pp. 51-77.

Millares Martínez, P.: «La sedería murciana en el siglo xvir: progresos y dificultades», en Aranda Pérez, F. J. (coord.): La declinación de la monarquia hispánica en el siglo XVII. Cuenca, 2004, pp. 543-555.

Monsalvo Antón, J. M.: «Aproximación al estudio del poder gremial en Castilla durante la Baja Edad Media: un escenario de debilidad», En la España medieval, 25, 2002, pp. 135-176.

Moor, T. de: «The Silent Revolution: A New Perspective on the Emergence of Commons, Guilds and other forms of Corporate Collective action in Western Europe», International Review of Social History, 53, 2008, pp. 179-212.

Navarro Espinach, G.: «Los negocios de la industria precapitalista valenciana en los siglos XIV-XVI», Revista d'Historia medieval, 11, 2000, pp. 67-104. 
JOSÉ ANTONIO MATEOS ROYO

POLÍTICA PÚBLICA Y PROTECCIONISMO CORPORATIVO:

INSTITUCIONES REGIONALES Y GREMIOS TEXTILES EN ARAGÓN DURANTE EL SIGLO XVII

Nieto Sánchez, J. A.: «Asociación y conflicto laboral en el Madrid del siglo XviıI», en López Barahona, V. y Nieto Sánchez, J. A. (eds.): El trabajo en la encrucijada. Artesanos urbanos en la Europa de la Edad Moderna. Madrid, 1996, pp. 248-287.

Nieto Sánchez, J. A.: Artesanos y mercaderes. Una historia social y económica del trabajo en Madrid, 1450-1850. Madrid, 2006.

North, D. C.: «Institutions, Transaction Costs and Productivity in the Long Run», Economic Inquiry, 25, 3, 1987, pp. 419-428.

OGILviE, S.: «Guilds, efficiency, and social capital: evidence from German proto-industry», The Economic History Review, 57, 2, 2004, pp 286-333.

Peiró Arroyo, A.: «Comercio de trigo y desindustrialización: las relaciones económicas entre Aragón y Cataluña", en Las relaciones económicas entre Aragón y Cataluña (siglos XVIII-XX). Huesca, 1990, pp. 35-64.

Peiró Arroyo, A.: Tiempo de industria. Zaragoza, 2000.

Peiró Arroyo, A.: Jornaleros y mancebos. Barcelona, 2002.

Perdices de Blas, L. y Sánchez Molledo, J. M. (eds.): Arbitrios sobre la economía aragonesa del siglo XVII. Zaragoza, 2007.

Pérez SARrión, G.: La península comercial. Mercado, redes sociales y Estado en España durante el siglo XVIII. Madrid, 2012.

Prak, M. Lis, C. Lucassen, J. y Soly, H. (eds.): Craft Guilds in the Early Modern Low Countries. Work, Power and Representation. Londres, 2006.

Redondo VeIntemillas, G.: Las corporaciones de artesanos de Zaragoza en el siglo XVII. Zaragoza, 1982.

Ruiz Martín, F.: La banca en España en 1782. Una historia económica del banco de España. Madrid, 1970.

Salas Ausens, J. A.: La población de Barbastro en los siglos XVI y XVII. Zaragoza, 1981.

Salas Ausens, J. A.: «La evolución demográfica aragonesa en los siglos XVI y XVII», en Nadal Oller, J. (ed.): La evolución demográfica bajo los Austrias. Alicante, 1991, pp. 169-179.

SÁNCHEZ BeLÉN, J. A.: «Medidas extraordinarias para una crisis económica: las reformas del duque de Medinaceli y del duque de Oropesa a finales del reinado de Carlos II», Trocadero, 23, 2011, pp. 7-35.

Sánchez Molledo, J. M.: Arbitristas aragoneses de los siglos XVI y XVII. Textos. Zaragoza, 2009.

SAN Vicente Pino, A.: Instrumentos para una historia social y económica del trabajo en Zaragoza durante los siglos XV a XVIII. Zaragoza, 1988.

Savall y Dronda P. y Penén Debesa, S.: Fueros, observancias y actos de Corte del reino de Aragón. Zaragoza, 1866.

Sanz Camañes, P.: Política, hacienda y milicia en el Aragón de los últimos Austrias entre 1640 y 1680. Zaragoza, 1997.

Sonenscher, M.: Work and Wages: Natural Law, Politics and the Eighteenth-century French Trades. Cambridge, 1989. 
JOSÉ ANTONIO MATEOS ROYO

POLÍTICA PÚBLICA Y PROTECCIONISMO CORPORATIVO:

INSTITUCIONES REGIONALES Y GREMIOS TEXTILES EN ARAGÓN DURANTE EL SIGLO XVII

Sugranies, J. A.: «La industria de la seda a Reus», en El món de la seda i Catalunya. Barcelona, 1991, pp. 213-223.

Torras Elías, J.: «Gremio, familia y cambio económico. Pelaires y tejedores en Igualada, 1695-1765», Revista de Historia Industrial, 2, 1992, pp. 11-30.

Torres, X.: «La Barcelona menestral en temps dels Austries», en Barcelona en temps dels Austries. La vita a la ciutat en el Renaixement i el Barroc (1492-1711). Barcelona, 1996, pp. 37-55.

Torró Gil, LL.: Abans de la indústria. Alcoi als inicis del sis-cents. Alicante, 1994.

Vázquez de Prada, V. y Molas Ribalta, P.: «La industria llanera a Barcelona. Segles XVI-XVII» en Molas Ribalta, P. (coord.): Economía i societat al segle XVIII. Barcelona, 1975, pp. 143-159.

Vega y LuQue, C. L. de la: «Historia y evolución de los gremios de Teruel», Teruel, 54, 1975, pp. 5-156 y 77-78, 1987, pp. 143-223.

Yun Casalilla, B.: Sobre la transición al capitalismo en Castilla. Economía y sociedad en Tierra de Campos (1500-1830). Valladolid, 1987.

Yun Casalilla, B.: «Manufacturas, mercado interior y redes urbanas: recesión, reajuste y rigideces», en Alcalá-Zamora, J. y Belenguer, E. (coords.): Calderón de la Barca y la España del Barroco. Madrid, 2001, vol. I, pp.111-127.

Zofío Llorente, J. C.: Gremios y artesanos en Madrid, 1550-1650: la sociedad del trabajo en una sociedad cortesana preindustrial. Madrid, 2005. 